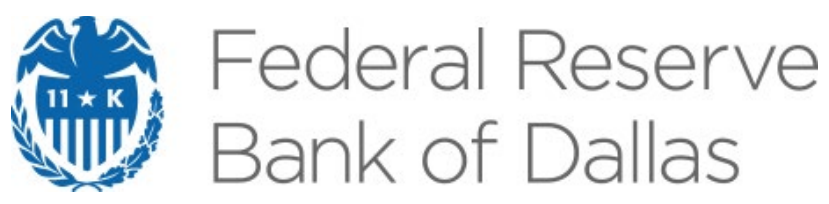

\title{
The Distributional Effects of COVID-19 and Optimal Mitigation Policies
}

Sewon Hur

Globalization Institute Working Paper 400 September 2020 (Revised October 2020)

Research Department https://doi.org/10.24149/gwp400r1

Working papers from the Federal Reserve Bank of Dallas are preliminary drafts circulated for professional comment. The views in this paper are those of the authors and do not necessarily reflect the views of the Federal Reserve Bank of Dallas or the Federal Reserve System. Any errors or omissions are the responsibility of the authors. 


\title{
The Distributional Effects of COVID-19 and Optimal Mitigation Policies*
}

\author{
Sewon Hur ${ }^{\dagger}$
}

This draft: October 2020

First draft: August 2020

\begin{abstract}
This paper develops a quantitative heterogeneous agent-life cycle model with a fully integrated epidemiological model in which economic decisions affect the spread of COVID-19 and, conversely, the virus affects economic decisions. The calibrated model is used to study the distributional consequences and effectiveness of two mitigation policies: a stay-at-home subsidy that subsidizes reduced hours worked and a stay-at-home order that limits outside hours. First, the stay-at-home subsidy is preferred because it reduces deaths by more and output by less, leading to a larger average welfare gain that benefits all individuals. Second, optimal mitigation policies involve a stay-at-home subsidy of \$450$\$ 900$ per week for $16-18$ months, depending on the welfare criterion. Finally, it is possible to simultaneously improve public health and economic outcomes, suggesting that debates regarding a supposed tradeoff between economic and health objectives may be misguided.
\end{abstract}

Keywords: pandemic, coronavirus, COVID-19, mitigation, tradeoffs.

JEL Classification Codes: D62, E21, E32, E62, I14, I15.

\footnotetext{
*An earlier version of this paper was circulated under the title "The Distributional Effects of COVID-19 and Mitigation Policies." I thank David Berger, Daniel Carroll, Andy Glover, Dirk Krueger, Karel Mertens, Charles Wyplosz, Kei-Mu Yi, and seminar participants at the Federal Reserve Bank of Dallas, the Fed Brown Bag, and the KAEA Macro Seminar for helpful discussions. I also thank Anna Eckert and Andrew Johnson for outstanding research assistance. This research was supported in part through computational resources provided by the Big-Tex High Performance Computing Group at the Federal Reserve Bank of Dallas. All codes and publicly available data used in this paper will be made available online in the near future. The views expressed herein are those of the author and not necessarily those of the Federal Reserve Bank of Dallas or the Federal Reserve System. First draft: August 2020.

†Sewon Hur, Federal Reserve Bank of Dallas, sewonhur@gmail.com.
} 


\section{Introduction}

Amid the deadliest pandemic since the 1918 influenza outbreak and the largest economic contraction since the Great Depression, policymakers and intellectuals continue to debate a supposed tradeoff between economic and public health outcomes. On one end of the spectrum, President Trump on May 6th, 2020, asked, "Will some people be affected badly?" and responded "Yes, but we have to get our country opened and we have to get it open soon." ${ }^{2}$ On the other end, New York Governor Cuomo on March 23rd, 2020, tweeted, "If it's public health versus the economy, the only choice is public health." ${ }^{3}$ In this paper, however, I show that it is possible to simultaneously improve public health and economic outcomes, suggesting that there need not be a tradeoff between economic and health objectives.

To better understand the economic-health tradeoff (or lack thereof), I build a quantitative model that I use as a laboratory to investigate the effects of various mitigation policies. Building on the economic-epidemiological model developed by Eichenbaum et al. (2020) that allows for rich feedback between economic activities and the spread of the virus, I add two important and necessary ingredients: heterogeneity in age and in income and wealth. Age heterogeneity is necessary to take into account that COVID-19 is particularly dangerous for older individuals, while mitigation policies, such as stay-at-home orders more adversely affect working-age individuals. Heterogeneity in income and wealth is necessary to consider the heterogeneous effects of mitigation policies, such as stay-at-home orders that may disproportionately harm low-wage workers, who are less likely to work from home, and low-wealth workers, who lack the resources to weather prolonged time away from work.

In the first part of the paper, I develop a quantitative heterogeneous agent-life cycle model with a fully integrated epidemiological model in which economic decisions such as consumption and outside labor affect the spread of COVID-19, and conversely, the virus affects economic decisions. The model also features endogenous labor with the option to work from home and hospital capacity constraints. At the time of writing, this is the only paper to develop a quantitative model that integrates economic-epidemiological feedback, heterogeneity across ages, and heterogeneity across income and wealth. For example, Kaplan et al. (2020) feature heterogeneity in income and wealth but not in ages; Glover et al. (2020)

\footnotetext{
${ }^{2}$ See https://www.cnbc.com/2020/05/05/trump-acknowledges-some-coronavirus-deaths-willresult-from-reopening.html.

${ }^{3}$ See https://twitter.com/nygovcuomo/status/1242264009342095361?lang=en.
} 
include heterogeneity in ages but not in income and wealth; and Bairoliya and Imrohoroglu (2020) model heterogeneity across age, income, and wealth, but do not allow economic activities to interact with the spread of the virus.

In the second part of the paper, I describe the model's calibration. The model is solved at a biweekly frequency to study the progression of the disease at a high frequency. The model's economic parameters are calibrated to match both aggregate and distributional features of the US economy prior to the pandemic and the model's epidemiological and clinical parameters are set to match features of COVID-19, such as estimates for the basic reproduction number and age-specific fatality rates. Acknowledging that there is quite a bit of uncertainty regarding these and other estimates, I conduct a host of sensitivity analyses, which also shed light on how changes in these estimates affect the optimal responses to the pandemic.

In the third part of the paper, I use the calibrated model to study the effectiveness of various mitigation policies. Specifically, I study a stay-at-home order (lockdown policy) that imposes a cap of 10 outside hours worked per week - resembling the various stay-at-home and shelter-in-place orders implemented by most states in response to the pandemic - and a stay-at-home subsidy (subsidy policy) that provides a weekly subsidy of $\$ 600$ for individuals who work less than 10 hours per week. Both policies begin March 27, 2020, and are gradually phased out after July 31, 2020. The subsidy policy has similarities to parts of the actual fiscal response-Pandemic Unemployment Assistance (PUA) program, which provided an additional $\$ 600$ in unemployment benefits, and, to a lesser extent, the Paycheck Protection Program (PPP), which provided funds to small businesses affected by the pandemic to pay furloughed workers. ${ }^{4}$ For expositional purposes, I refer to US policy as the implementation of both the subsidy and lockdown policies.

Finally, I investigate the properties of optimal mitigation policies. Specifically, I vary the subsidy amount from $\$ 0$ to $\$ 1,800$ per week, the subsidy duration from 2 to 22 months, the hours threshold to qualify for the subsidy from 0 to 10 hours per week, with and without a lockdown. Here, I utilize high performance computing to solve for over 16,000 transition

\footnotetext{
${ }^{4}$ There are also notable differences. The first is that while the PUA subsidy requires involuntary unemployment or underemployment, the subsidy studied in this model is based on voluntary reductions in hours worked. The second is that the model subsidy is funded by a consumption tax, whereas the PUA and PPP programs are debt-financed. I provide a more detailed description of the similarities and differences in Section 4.2 .
} 
paths, including sensitivity analyses.

The main findings are summarized below.

\section{Even in the absence of mitigation policies, private mitigation by individ-} uals is substantial. Individuals voluntarily reduce their consumption and outside hours worked to reduce their probability of infection. While this is a common feature in economic-epidemiological models such as Eichenbaum et al. (2020), the rich heterogeneity in my model allows for additional new insights. All else equal, private mitigation is stronger for older individuals who face higher death rates if infected, for higher-wage workers who are more likely to work from home, and for wealthier individuals who can afford to sustain prolonged time away from work. This highlights the key externality: young low wage-low wealth workers engage in too much economic activity, relative to the social optimum, leading to higher infections and deaths in the aggregate. Additionally, the fact that low-wage workers reduce their consumption and outside hours by less than their high-wage counterparts is also qualitatively consistent with the fact documented by Chetty et al. (2020) that higher income locations had larger declines in spending and mobility than lower income locations.

2. The stay-at-home subsidy is superior to the stay-at-home order along all the relevant dimensions. Relative to the lockdown policy alone, the subsidy policy alone delivers a higher average welfare gain and reduces deaths by more and output by less. In the case of the lockdown, older individuals experience a welfare gain because of the reduced infection and death probability, but these gains are mostly offset by the welfare losses of the young, low-wage/low-wealth workers, who face a large decline in their income. In contrast, the stay-at-home subsidy benefits all individuals, making it a Pareto improvement. This contrast arises because while both policies result in reduced economic activities of young, low-wage/low-wealth workers, the subsidy policy provides the incentives to do so and the lockdown does not. Neither policy has a direct effect

on the labor supply of high-wage individuals, who choose to work mostly from home during the pandemic.

3. Optimal policies involve larger and longer duration subsidies compared with current US policy. I refer to the constrained optimum the policy configuration that delivers the highest average welfare gain, conditional on full support (i.e. Pareto im- 
provements). The constrained optimum involves a larger subsidy ( $\$ 900$ per week), longer duration (18 months), a lower qualifying threshold (zero hours), and no lockdown, compared with the configuration that most resembles US policy. The constrained optimum reduces deaths by 0.7 and 0.3 percentage points but reduces two-year output by 4.5 and 2.2 percentage points, compared with no mitigation and US policy, respectively.

\section{It is possible to simultaneously improve public health and economic objec-} tives. The output maximizing policy, which involve a weekly subsidy of $\$ 450$, duration of 16 months, a zero hour qualifying threshold, and no lockdown, reduces deaths by 0.4 percentage points and increases two-year output by 5.5 percentage points, compared with no mitigation. Furthermore, this policy also benefits all individuals. Notably, the output maximizing policy delivers a similar reduction in deaths as US policy but improves two-year output by 7.8 percentage points. Compared with no mitigation, the increase in output is the result of two opposing effects. The first is the direct (selection) effect: the subsidy provides an incentive to reduce hours, which leads to less output. This effect is negligible for subsidies less than $\$ 600$ per week because they only change the behavior of low-wage workers. The second is the indirect (public health) effect: The reduction in infection and death probabilities that result from the mitigation policy partly reverses the voluntary reductions in hours worked from higher-wage workers. For mitigation policies with moderate subsidy amounts, the indirect effect dominates, improving both economic and health objectives. For larger subsidy amounts, the direct effect can dominate the indirect effect, leading to a decline in output.

Related literature. The epidemiological part of the model borrows from the SIR model of disease transmission, originally developed by Kermack and McKendrick (1927). Atkeson (2020) was one of the first papers to use the SIR model in an economics context. The literature that uses the SIR framework in an economic context is already very large and rapidly expanding. Alvarez et al. (2020), Eichenbaum et al. (2020), Farboodi et al. (2020), and Jones et al. (2020) study optimal mitigation in SIR models extended with lockdowns, economic-epidemiological feedback, social distancing, and work from home with learningby-doing, respectively. Bodenstein et al. (2020), Baqaee et al. (2020), and Krueger et al. (2020) study the SIR model with multiple sectors. Birinci et al. (2020), Garibaldi et al. 
(2020), and Kapicka and Rupert (2020) incorporate search and matching frictions into the SIR framework, while Berger et al. (2020), Chari et al. (2020), and Piguillem and Shi (2020) extend the SIR model to focus on testing and quarantine. Argente et al. (2020) and Azzimonti et al. (2020) enrich the SIR model with city structure and contact networks, respectively. Bognanni et al. (2020) develop a SIR model with multiple regions and estimate it on daily county-level US data. Aum et al. (2020) study the effects of lockdowns in a model with heterogeneous age, skill, and occupation choice. ${ }^{5}$

This paper is most related to Bairoliya and Imrohoroglu (2020), Glover et al. (2020), and Kaplan et al. (2020). Bairoliya and Imrohoroglu (2020) study quarantine policies in a life-cycle model with heterogeneity across age, health, income, and wealth. They primarily focus on the effects of selective quarantines based on age and health. Relative to my paper, Bairoliya and Imrohoroglu (2020) study the disease progression at a lower frequency (yearly) and do not incorporate the economic-epidemiological feedback channel. Glover et al. (2020) study optimal mitigation policies in a model with three types of agents: retirees, young workers in the essential sector, and young workers in the non-essential sector. Relative to Glover et al. (2020), my paper features heterogeneity across not only age, but also income and wealth, and complements both Bairoliya and Imrohoroglu (2020) and Glover et al. (2020) by analyzing mitigation policies specifically targeting the behavior of these groups. Kaplan et al. (2020) do not model heterogeneity by age, but include heterogeneity across income, wealth, sector, and occupation. Like my paper, they focus on policies that improve not only average outcomes but also account for the distributional consequences of mitigation policies. Relative to Kaplan et al. (2020), my paper addresses the externalities that are generated by the differential effects of COVID-19 by age. It also explicitly accounts for the value of life so that individual welfare changes directly reflect economic as well as expected health outcomes and proposes a specific set of policies that can improve aggregate outcomes in a Pareto improving sense.

This paper is structured as follows. The next section presents the model. Section 3 describes the calibration of the model's economic and epidemiological parameters. In Section 4, the calibrated model is used to investigate the role of private mitigation and the welfare consequences of the pandemic and mitigation policies. Section 5 discusses the properties of

\footnotetext{
${ }^{5}$ Given the rapidly expanding literature, this is likely not an exhaustive list. I refer the reader to Brodeur et al. (2020) and Hur and Jenuwine (2020) for a review of this literature.
} 
optimal policies. Finally, section 6 concludes.

\section{Model}

This section presents a model economy used to quantitatively analyze the welfare consequences of COVID-19 and to run policy counterfactuals. The setting combines the heterogeneousagent overlapping-generations model with an economic-epidemiological model that resembles those used in Eichenbaum et al. (2020). The economy is inhabited by overlapping generations of stochastically aging individuals. Time is discrete and indexed by $t=0, \ldots, \infty$. Workers face idiosyncratic efficiency shocks and borrowing constraints within an incomplete market setting. I now describe the model in more detail.

\section{$2.1 \quad$ Individuals}

Individuals of age $j \in J \equiv\{1,2, . ., \bar{J}\}$ face conditional aging probabilities given by $\left\{\psi_{j}\right\}{ }^{6}$ Mandatory retirement occurs at age $j=J_{R}$. The period utility function is given by

$$
u(c, \ell, h)=\frac{c^{1-\sigma}}{1-\sigma}-\varphi \frac{\ell^{1+\nu}}{1+\nu}+\bar{u}+\hat{u}_{h}
$$

where $c$ is consumption, $\ell$ is labor supply, and $\bar{u}$ and $\hat{u}_{h}$ govern the flow value of being alive and being in health state $h$, respectively.

An individual's health status is given by $h \in\{S, I, R, D\}$ : susceptible agents are healthy but may contract the virus, infected agents have contracted the virus and may pass it onto others, and agents that exit the infection can either recover or die. Recovered agents are assumed to be immune from further infection. ${ }^{7}$ The transition between health states builds on the widely used SIR model, originally developed by Kermack and McKendrick (1927). Susceptible individuals get infected with probability $\pi_{I t}$, which depends on individual consumption and outside labor $\left(c, \ell^{o}\right)$ and the aggregate measure of infected individuals $\left(\mu_{I t}\right)$ and their consumption and outside labor $\left(C_{I t}, L_{I t}^{o}\right)$. Formally,

$$
\pi_{I t}\left(c, \ell^{o} ; Z_{t}\right)=\beta_{c} c C_{I t}+\beta_{\ell} \ell^{o} L_{I t}^{o}+\beta_{e} \mu_{I t},
$$

\footnotetext{
${ }^{6}$ Given that the model will be used to analyze disease progression at a high frequency, the assumption of stochastic aging greatly reduces the state space and computational burden.

${ }^{7}$ At this point, it is not clear whether individuals that have recovered from COVID-19 have lasting immunity. One could easily extend the model to have shorter durations of immunity.
} 
where $Z_{t} \equiv\left\{\mu_{I t}, C_{I t}, L_{I t}^{o}\right\}$. This framework allows the virus to be contracted from consumptionrelated activities, labor-related activities, and from other settings. It also allows a feedback between disease progression and economic activities as in Eichenbaum et al. (2020), Glover et al. (2020), and Jones et al. (2020).

Infected individuals exit the infection with probability $\pi_{X t}$ and upon exit, they recover with probability $1-\delta_{j t}\left(\mu_{I t}\right)$ and die with probability $\delta_{j t}\left(\mu_{I t}\right)$. The fatality rate depends on the individual's age and on the aggregate measure of infected individuals, reflecting hospital capacity constraints. If we assume that a vaccine and cure are developed and implemented in period $\hat{t}$, then the transition matrix between health states, for $t<\hat{t}$, is given by

$$
\begin{aligned}
& \begin{array}{c|cccc} 
& S & I & R & D \\
\hline S & 1-\pi_{I t}\left(c, \ell^{o} ; Z_{t}\right) & \pi_{I t}\left(c, \ell^{o} ; Z_{t}\right) & 0 & 0
\end{array}
\end{aligned}
$$

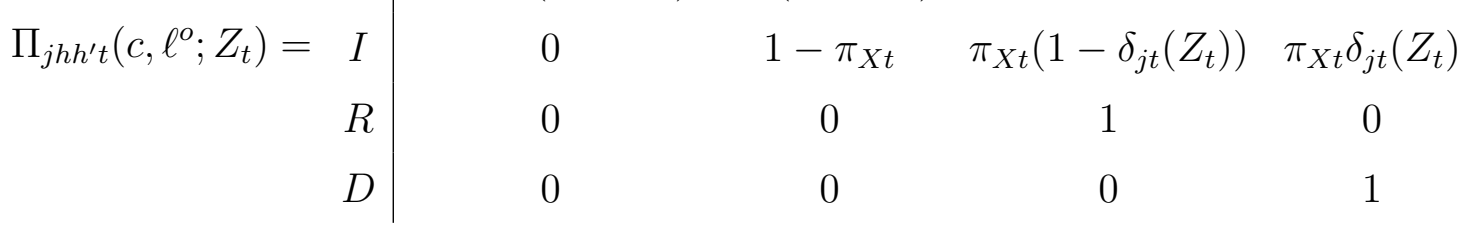

and for $t \geq \hat{t}$

$$
\Pi_{j h h^{\prime} t}\left(c, \ell^{o} ; Z_{t}\right)=\begin{array}{c|cccc} 
& S & I & R & D \\
\hline S & 0 & 0 & 1 & 0 \\
I & 0 & 0 & 1 & 0 \\
R & 0 & 0 & 1 & 0 \\
D & 0 & 0 & 0 & 1
\end{array} .
$$

Each period, workers receive idiosyncratic efficiency shocks $\varepsilon \in E$, which follows a Markov process, with transition matrix $\Gamma$. Their labor income is given by $w_{t} \eta_{j h} \varepsilon \ell$, where $w_{t}$ is the efficiency wage, $\eta_{j h}$ is the health- and age-profile of efficiency units, and $\ell$ is total hours worked. Workers may choose to work up to a fraction $\bar{\theta}_{j}(\varepsilon)$ of their labor hours from home, where $\bar{\theta}_{j}(\varepsilon)$ is allowed to vary by age and efficiency. Retirees are assumed to receive a fixed income of $s$ each period. ${ }^{8}$ Individuals can accumulate non-contingent assets $k$, which delivers a net return of $r_{t}$.

Given the sequence of prices $\left\{w_{t}, r_{t}\right\}$ and aggregate states $\left\{Z_{t}\right\}$, a retiree with age $j \geq J_{R}$,

\footnotetext{
${ }^{8}$ This can readily be extended to depend on lifetime earnings as in Hur (2018).
} 
wealth $k$, and health $h$ in period $t$ chooses consumption $c$ and savings $k^{\prime}$ to solve:

$$
\begin{array}{rl}
v_{j t}^{R}(k, h)=\max _{c, k^{\prime} \geq 0} & u(c, 0, h)+\beta \psi_{j} \sum_{h^{\prime} \in H} \Pi_{h h^{\prime} t}(c, 0) v_{j+1, t+1}^{R}\left(k^{\prime}, h^{\prime}\right) \\
& +\beta\left(1-\psi_{j}\right) \sum_{h^{\prime} \in H} \Pi_{h h^{\prime} t}(c, 0) v_{j, t+1}^{R}\left(k^{\prime}, h^{\prime}\right) \\
\text { s.t. } & c+k^{\prime} \leq s+k\left(1+r_{t}\right)
\end{array}
$$

where $\beta$ is the time discount factor and $H=\{S, I, R\}$. Solving this yields retiree policy functions $\left\{c_{j}^{R}(k, h), k_{j}^{R^{\prime}}(k, h)\right\}_{j \geq J_{R}}$ for consumption and savings, respectively. I assume that the value of death is zero and that $v_{\bar{J}+1, t}^{R}=0$, which implies that agents in the last stage of life $(j=\bar{J})$ may die due to stochastic aging and, if infected, due to the virus.

Given the sequence of prices $\left\{w_{t}, r_{t}\right\}$, labor income taxes $\left\{\tau_{\ell t}\right\}$, and aggregate states $\left\{Z_{t}\right\}$, a worker with age $j<J_{R}$, wealth $k$, efficiency $\varepsilon$, and health $h$ in period $t$ chooses consumption $c$, total labor $\ell$, outside labor $\ell^{\circ}$, and savings $k^{\prime}$ to solve:

$$
\begin{array}{rl}
v_{j t}(k, \varepsilon, h)=\max _{c, \ell, \ell^{o}, k^{\prime} \geq 0} & u(c, \ell, h)+\beta \psi_{j} \sum_{\varepsilon^{\prime} \in E h^{\prime} \in H} \Gamma_{\varepsilon \varepsilon^{\prime}} \Pi_{h h^{\prime} t}\left(c, \ell^{o}\right) v_{j+1, t+1}\left(k^{\prime}, \varepsilon^{\prime}, h^{\prime}\right) \\
& +\beta\left(1-\psi_{j}\right) \sum_{\varepsilon^{\prime} \in E h^{\prime} \in H} \sum_{\varepsilon \varepsilon^{\prime}} \Pi_{h h^{\prime} t}\left(c, \ell^{o}\right) v_{j, t+1}\left(k^{\prime}, \varepsilon^{\prime}, h^{\prime}\right) \\
\text { s.t. } c+k^{\prime} \leq w_{t} \eta_{j}^{h}\left(1-\tau_{\ell t}\right) \varepsilon \ell+k\left(1+r_{t}\right) \\
\left(1-\bar{\theta}_{j}(\varepsilon)\right) \ell \leq \ell^{o} \leq \ell
\end{array}
$$

where $v_{j t}(k, \varepsilon, h)=v_{j t}^{R}(k, h)$ for $j \geq J_{R}$ and $\varepsilon \in E$. Solving this yields worker policy functions $\left\{c_{j}(k, \varepsilon, h), \ell_{j}(k, \varepsilon, h), \ell_{j}^{o}(k, \varepsilon, h), k_{j}^{\prime}(k, \varepsilon, h)\right\}_{j<J_{R}}$ for consumption, labor, outside labor, and savings, respectively. Additionally, let $c_{j}(k, \varepsilon, h)=c_{j}^{R}(k, h)$ and $k_{j}^{\prime}(k, \varepsilon, h)=k_{j}^{R^{\prime}}(k, h)$ for $j \geq J_{R}$ and $\varepsilon \in E$.

\subsection{Production}

A representative firm hires labor $\left(L_{f t}\right)$ and capital $\left(K_{f t}\right)$ to produce according to

$$
Y_{f t}=K_{f t}^{\alpha} L_{f t}^{1-\alpha} .
$$

Taking prices as given, the firm solves

$$
\max _{L_{f t}, K_{f t}} Y_{f t}-w_{t} L_{f t}-\left(r_{t}+\delta\right) K_{f t}
$$


where $\delta$ is the deprecation rate of capital. Optimality conditions are given by

$$
\begin{aligned}
& w_{t}=(1-\alpha) K_{f t}^{\alpha} L_{f t}^{-\alpha}, \\
& r_{t}=\alpha K_{f t}^{\alpha-1} L_{f t}^{1-\alpha}-\delta .
\end{aligned}
$$

\subsection{Law of motion for aggregate states}

Let $C_{j h t}$ and $L_{j h t}^{o}$ denote aggregate consumption and outside labor, respectively, of individuals with age $j$ and health $h$ in period $t$. Then, by the law of large numbers, equation (2) implies that new infections within an age- $j$ cohort are given by

$$
T_{j t}=\beta_{c} C_{j S t} C_{I t}+\beta_{\ell} L_{j S t}^{o} L_{I t}^{o}+\beta_{e} \mu_{j S t} \mu_{I t}
$$

where $\mu_{j S t}$ is the measure of susceptible age- $j$ individuals in period $t$. The measure of infected agents is then given by $\mu_{I, t+1}=\sum_{j \in J} \mu_{j I, t+1}$ where, for $j>1$,

$$
\begin{aligned}
\mu_{j I, t+1}= & \psi_{j-1}\left(\mu_{j-1, I t}\left(1-\pi_{X t}\right)+T_{j-1, t}\right) \\
& +\left(1-\psi_{j}\right)\left(\mu_{j I t}\left(1-\pi_{X t}\right)+T_{j t}\right),
\end{aligned}
$$

and

$$
\mu_{1 I, t+1}=\left(1-\psi_{1}\right)\left(\mu_{1 I t}\left(1-\pi_{X t}\right)+T_{1 t}\right) .
$$

\subsection{Equilibrium}

We are ultimately interested in studying disease dynamics along a transition path. However, because most of the model parameters are calibrated to an initial pre-pandemic steady state, let's first define a stationary equilibrium in which $\mu_{I}=0$. In this case, aggregate consumption and labor of infected individuals is trivially zero. Thus $Z=(0,0,0)$ and $\Pi$ is the identity matrix. Define the state space over wealth, efficiency, and health as $X=K \times E \times H$ and let a $\sigma$-algebra over $X$ be defined by the Borel sets, $\mathcal{B}$, on $X$.

Definition. A stationary recursive competitive equilibrium, given fiscal policies $\left\{\tau_{c}, \tau_{\ell}, s\right\}$, is a set of value functions $\left\{v_{j}\right\}_{j \in J}$, policy functions $\left\{c_{j}, \ell_{j}, \ell_{j}^{o}, k_{j}^{\prime}\right\}_{j \in J}$, prices $\{w, r\}$, producer

plans $\left\{Y_{f}, L_{f}, K_{f}\right\}$, the distribution of newborns $\omega$, and invariant measures $\left\{\mu_{j}\right\}_{j \in J}$ such that: 
1. Given prices, retirees and workers solve (28) and (6), respectively.

2. Given prices, firms solve (8).

3. Markets clear:

(a) $Y_{f}=\int_{X} \sum_{j \in J}\left(c_{j}(k, \varepsilon, h)+\delta k\right) d \mu_{j}(k, \varepsilon, h)$,

(b) $L_{f}=\int_{X} \sum_{j<J_{R}} \ell_{j}(k, \varepsilon, h) d \mu_{j}(k, \varepsilon, h)$,

(c) $K_{f}=\int_{X} \sum_{j \in J} k d \mu_{j}(k, \varepsilon, h)$.

4. The government budget constraint holds:

$$
\tau_{\ell} w \int_{X} \sum_{j<J_{R}} \eta_{j h} \varepsilon \ell_{j}(k, \varepsilon, h) d \mu_{j}(k, \varepsilon, h)=s \int_{X} \sum_{j \geq J_{R}} d \mu_{j}(k, \varepsilon, h) .
$$

5. For any subset $(\mathcal{K}, \mathcal{E}, \mathcal{H}) \in \mathcal{B}$, the invariant measure $\mu_{j}$ satisfies, for $j>1$,

$$
\begin{aligned}
\mu_{j}(\mathcal{K}, \mathcal{E}, \mathcal{H}) & =\int_{X} \psi_{j-1} \mathbb{1}_{\left\{k_{j-1}^{\prime}(k, \varepsilon, h) \in \mathcal{K}\right\}} \sum_{\varepsilon^{\prime} \in \mathcal{E} h^{\prime} \in \mathcal{H}} \sum_{\varepsilon \varepsilon^{\prime}} \Pi_{h h^{\prime}} d \mu_{j-1}(k, \varepsilon, h) \\
& +\int_{X}\left(1-\psi_{j}\right) \mathbb{1}_{\left\{k_{j}^{\prime}(k, \varepsilon, h) \in \mathcal{K}\right\}} \sum_{\varepsilon^{\prime} \in \mathcal{E} h^{\prime} \in \mathcal{H}} \sum_{\varepsilon \varepsilon^{\prime}} \Pi_{h h^{\prime}} d \mu_{j}(k, \varepsilon, h)
\end{aligned}
$$

and

$$
\mu_{1}(\mathcal{K}, \mathcal{E}, \mathcal{H})=\int_{X}\left(1-\psi_{1}\right) \mathbb{1}_{\left\{k_{1}^{\prime}(k, \varepsilon, h) \in \mathcal{K}\right\}} \sum_{\mathcal{E}^{\prime} \in \mathcal{E} h^{\prime} \in \mathcal{H}} \sum_{\varepsilon \varepsilon^{\prime}} \Pi_{h h^{\prime}} d \mu_{1}(k, \varepsilon, h)+\omega(\mathcal{K}, \mathcal{E}, \mathcal{H})
$$

6. The newborn distribution satisfies:

$$
\int_{X} k d \omega(k, \varepsilon, h)=\int_{X} \psi_{\bar{J}} k_{\bar{J}}^{\prime}(k, \varepsilon, h) d \mu_{\bar{J}}(k, \varepsilon, h) .
$$

\section{Calibration}

In this section, I begin by calibrating some of the model's parameters to the pre-pandemic steady state and discuss how other parameters are set. I will then use the calibrated model to analyze the distributional effects of the pandemic and mitigation policies. The parameters are summarized in Tables 1 and 2. See Appendix C for details regarding the computation and calibration strategy. 


\subsection{Economic parameters}

A period in the model is two weeks. The aggregate measure of individuals in the steady state economy is normalized to one. The number of age cohorts, $J$, is set to 3 , so that $j=1$ corresponds to ages 25-44 (young), $j=2$ corresponds to ages 45-64 (middle), and $j=J_{R}=\bar{J}=3$ corresponds to ages $65-84$ (old). The aging probability $\psi_{j}=\psi$ is set so that agents spend, on average, 20 years in each age cohort. The wealth of deceased individuals are rebated to a fraction of newborn individuals each period. Specifically, 85 percent of individuals are born with zero wealth, whereas 15 percent of individuals are endowed with 28 times annual per capita consumption. ${ }^{9}$

The age-profile of efficiency units, $\eta_{j S}$, is normalized to one for healthy young workers and healthy middle-age workers are assumed to be 35 percent more efficient, to match the wage ratio in the data (2014, Panel Survey of Income Dynamics). I assume that the efficiencies of recovered individuals are the same as those of susceptible individuals, $\eta_{j R}=\eta_{j S} \cdot{ }^{10}$ The fraction of labor that can be done from home, $\bar{\theta}_{j}(\varepsilon)$ is set to match the average share of jobs that can be done from home by occupations grouped into five wage bins, computed based on Dingel and Neiman (2020). The average share of jobs that can be done from home is 0.03 for the occupations in the bottom 20 percent of the wage distribution, 0.21 for the second quintile, 0.32 for the third quintile, 0.47 for the fourth quintile, and 0.66 for occupations in the top 20 percent of the wage distribution.

The time discount factor $\beta$ is chosen so that the model replicates the US net-worth-toGDP ratio (2014, US Financial Accounts). The parameter that governs the disutility from labor, $\varphi$, is set so that the model generates a share of disposable time spent working of 0.3 , equivalent to 30 hours per week. I set risk aversion, $\sigma$, to be 2 and the Frisch elasticity, $1 / \nu$, to be 0.5 , which are both standard values in the literature.

To set the flow value of life, I follow Glover et al. (2020) and Greenstone and Nigam (2020) who use a value of statistical life (VSL) of $\$ 11.5$ million, which corresponds to 7,475

\footnotetext{
${ }^{9}$ This is based on the fact that 85 percent of households whose heads are between the ages of 21 and 25 had a cumulative net worth of zero in 2016 (Survey of Consumer Finances). The calibrated value of the endowment is rather large. One way to address this issue would be to increase the number of age cohorts so that retired individuals draw down more wealth before dying.

${ }^{10}$ It is too early to conclude about the potentially long-lasting consequences of COVID-19. That said, these assumptions can easily be modified if evidence dictates.
} 
times biweekly consumption per capita in the United States. ${ }^{11}$ For simplicity, I assume that the VSL is computed based on the consumption of a healthy infinitely-lived representative agent that discounts time at the rate of $\beta(1-\psi)$ in the pre-pandemic steady state, whose present discounted utility is given by

$$
v=\frac{\left(\bar{c}+\Delta_{c}\right)^{1-\sigma}}{1-\sigma}+\bar{u}+\frac{\beta\left(1-\psi+\Delta_{\psi}\right)}{1-\beta(1-\psi)}\left(\frac{\bar{c}^{1-\sigma}}{1-\sigma}+\bar{u}\right)
$$

where $\bar{c}$ denotes steady state consumption per capita and $\Delta_{c}$ and $\Delta_{\psi}$ denote small one-time deviations to consumption and survival probability. Then, the VSL - defined as the marginal rate of substitution between survival and consumption - can be expressed as

$$
V S L=\left.\frac{\frac{\partial v}{\partial \Delta_{\psi}}}{\frac{\partial v}{\partial \Delta_{c}}}\right|_{\Delta_{c}=0}=\frac{\beta}{1-\beta(1-\psi)} \frac{\frac{\bar{c}^{1-\sigma}}{1-\sigma}+\bar{u}}{\bar{c}^{-\sigma}} .
$$

Then, by substituting $V S L=7475 \times \bar{c}$, we obtain

$$
\bar{u}=7475 \times \bar{c}^{1-\sigma} \frac{1-\beta(1-\psi)}{\beta}-\frac{\bar{c}^{1-\sigma}}{1-\sigma} .
$$

The capital elasticity in the production function, $\alpha$, is set to match the aggregate capital income share of 0.36. The labor income tax $\tau_{\ell}$ and retirement income $s$ are chosen so that retirement income is 30 percent of average labor earnings in the model and the government budget constraint is satisfied. The depreciation rate of capital, $\delta$, is set at an annualized rate of 5 percent per year.

The labor efficiency shocks $\varepsilon$ are assumed to follow an order-one autoregressive process as follows:

$$
\log \varepsilon_{t}=\rho_{\varepsilon} \log \varepsilon_{t-1}+v_{t}, v_{t} \sim N\left(0, \sigma_{v}^{2}\right) .
$$

This process is estimated using annual wages constructed from the PSID to find a persistence of $\rho_{\varepsilon}=0.94$ and a standard deviation of $\sigma_{v}=0.19 .{ }^{12}$ These parameters are then converted to a higher frequency, following Krueger et al. (2016). The process is approximated with a seven-state Markov process using the Rouwenhurst procedure described in Kopecky and Suen (2010).

\footnotetext{
${ }^{11}$ To arrive at $\$ 11.5$ million, Greenstone and Nigam (2020) use the $\$ 9.9$ million in 2011 dollars used in U.S. Environmental Protection Agency (2015), and adjust for inflation. As a robustness check, I use a lower VSL recommended in U.S. Environmental Protection Agency (2020), which is $\$ 7.4$ million in 2006 dollars, or 6,208 times biweekly consumption per capita in 2006. The main results of the paper are robust to this lower value.

${ }^{12}$ The wages are constructed similarly to Floden and Lindé (2001) and the sample selection and estimation procedures closely follow Krueger et al. (2016) and Carroll and Hur (2020). See Appendix A for details.
} 
Table 1: Calibration of economic parameters

\begin{tabular}{lll}
\hline Parameters & Values & Targets / Source \\
\hline \hline Discount factor, annualized, $\beta$ & 0.97 & Wealth-to-GDP: 4.81 (2014) \\
Risk aversion, $\sigma$ & 2 & Standard value \\
Disutility from labor, $\varphi$ & 114 & Average hours: 30 hours per week \\
Frisch elasticity, $1 / \nu$ & 0.50 & Standard value \\
Flow value of life, $\bar{u}$ & 9.51 & Value of statistical life: $\$ 11.5$ million \\
Aging probability, annualized, $\psi$ & 0.05 & Expected duration: 20 years \\
Efficiency units, $\eta_{j S}=\eta_{j R}$ & $\{1,1.35\}_{j=1,2}$ & Wage ratio of age 45-64 workers \\
& & to age $25-44$ workers (PSID) \\
Factor elasticity, $\alpha$ & 0.36 & Capital share \\
Capital depreciation, annualized, $\delta$ & 0.05 & Standard value \\
Retirement income, $s$ & 1.00 & $30 \%$ of average earnings per worker \\
Labor income tax, $\tau_{\ell}$ & 0.15 & Government budget constraint \\
Persistence, annual, $\rho_{\varepsilon}$ & 0.94 & Author estimates (PSID) \\
Standard deviation, annual, $\sigma_{v}$ & 0.19 & Author estimates (PSID) \\
\hline
\end{tabular}

\subsection{Parameters related to COVID-19}

The exit rate, $\pi_{X}$ is set to $14 / 18$ so that the expected duration of the infection is 18 days, as in Atkeson (2020) and Eichenbaum et al. (2020). For the unconstrained case fatality rates, I use data from South Korea's Ministry of Health and Welfare (accessed August 4, 2020) to compute a fatality rate of 8.47 percent for ages $65-84,0.94$ percent for ages $45-64$, and 0.09 percent for ages 25-44. I use South Korean data because testing has been abundant since the outbreak began ${ }^{13}$, the peak in infections was early enough that case fatality rates are not biased due to lags in deaths, and hospitals were not overwhelmed, as the number of active cases never exceeded 0.015 percent of the population. ${ }^{14}$

Next, I discuss the hospital capacity constraints and how they affect death rates. Fol-

\footnotetext{
${ }^{13}$ For example, see https://www.bloomberg.com/news/articles/2020-04-18/seoul-s-full-cafes-apple-storelines-show-mass-testing-success. Aum et al. (2020) also discuss the success of early testing and tracing efforts in South Korea.

${ }^{14}$ Active infection cases in South Korea peaked at 7,362 on March 11, 2020, according to https: //www.worldometers.info/coronavirus/country/south-korea/
} 
lowing Piguillem and Shi (2020), I use the functional form

$$
\delta_{j}\left(\mu_{I}\right)=\delta_{j}^{u} \min \left\{1, \frac{\kappa}{\mu_{I}}\right\}+\delta_{j}^{c} \max \left\{0,1-\frac{\kappa}{\mu_{I}}\right\}
$$

where $\delta_{j}^{u}$ and $\delta_{j}^{c}$ denote the unconstrained and untreated death rates and $\kappa$ denotes the measure of infected individuals that can be treated without the constraint binding. According to the American Hospital Association, there are roughly 924,000 hospital beds in the US, corresponding to 0.28 percent of the population. ${ }^{15}$ Since not all infected cases require hospitalization, I use a generous capacity constraint, $\kappa$, of 1 percent. ${ }^{16}$ The unconstrained death rates, $\delta_{j}^{u}$, are set to match those documented for South Korea, and the untreated death rates are set as $\delta_{j}^{c}=2 \delta_{j}^{u}$, following Piguillem and Shi (2020).

There is quite a bit of uncertainty regarding the basic reproduction number $\left(R_{0}\right)$, which corresponds to the number of people to whom the average infected person passes the disease absent mitigation efforts. Most estimates range between 2.2 and 3.1 (see for example, Wang et al. 2020 and Fauci et al. 2020), so I use a conservative estimate of 2.2. ${ }^{17}$ Using equation (11), total new infections in a given period is given by

$$
T=\beta_{c} C_{S} C_{I}+\beta_{\ell} L_{S}^{o} L_{I}^{o}+\beta_{e} \mu_{S} \mu_{I}
$$

where $C_{h}$ and $L_{h}^{o}$ are the aggregate steady state consumption and outside labor of individuals with health status $h \in H$. In the pre-pandemic steady state, workers are indifferent between working outside or working from home. Thus, I assume that all steady state work is done outside, which can be obtained by introducing an arbitrarily small difference in either efficiency or preference in favor of working outside. If we assume that when the virus is first introduced into the model, we have that $L_{S} / \mu_{S}=L_{I} / \mu_{I}$ and $C_{S} / \mu_{S}=C_{I} / \mu_{I}$, then by taking $\mu_{S} \rightarrow 1$, the basic reproduction number is given by ${ }^{18}$

$$
R_{0}=\frac{\beta_{c} C_{S}^{2}+\beta_{\ell} L_{S}^{2}+\beta_{e}}{\pi_{X}}
$$

Thus given values for the basic reproduction number, $R_{0}$, the exit rate, $\pi_{X}$, the steady state values for aggregate consumption and labor, $C_{S}$ and $L_{S}$, we need to assign values to the

\footnotetext{
${ }^{15}$ See https://www.aha.org/statistics/fast-facts-us-hospitals.

${ }^{16}$ I present sensitivity analysis to a higher capacity constraint in Section 5.1.

${ }^{17}$ I present sensitivity analysis to a higher value for the basic reproduction number in Section 5.1.

${ }^{18}$ These assumptions allow the calibration of these epidemiological parameters using steady state values. These may also be reasonable assumptions, given that the very first infected individuals may not change their behavior given the lack of testing and information regarding the pandemic in the early stages.
} 
fractions of new infections occurring through consumption activities, work activities, and other channels to pin down the values for $\beta_{c}, \beta_{\ell}$, and $\beta_{e}$. Evidence on how COVID-19 is transmitted is limited, but in the case of other infectious diseases, Ferguson et al. (2006) report that 70 percent of transmissions occur outside of the household. In another study that investigates the transmission channels of infectious diseases, Mossong et al. (2008) find that 35 percent of high-intensity contacts occur in workplaces and schools. Based on these studies, I assume that one-third of initial transmission occurs through consumption activities, one-third through labor activities, and one-third through other channels. ${ }^{19}$

For the value of being infected, Glover et al. (2020) assume a 30 percent reduction in the flow value of life for an average infected agent with mild symptoms and a 100 percent reduction in the flow value of life for an average infected agent with severe symptoms. I take an intermediate value of 50 percent by setting $\hat{u}_{I}=-0.5\left(\bar{c}^{1-\sigma} /(1-\sigma)+\bar{u}\right)$ and set $\hat{u}_{S}=\hat{u}_{R}=0 .^{20}$

Next, I discuss how the efficiency units change when an individual gets infected. It is reasonable to expect that those with no symptoms would suffer little, if any, efficiency loss, whereas those that experience very severe symptoms would suffer something close to a 100 percent efficiency loss. Without sufficient evidence regarding how COVID-19 affects labor efficiency and the fraction of infected individuals suffering severe symptoms, I assume that infected individuals suffer a 50 percent loss in efficiency. ${ }^{21}$

\section{Pandemic}

This section uses the model to investigate the distributional consequences of the pandemic and various mitigation measures. First, I explore how the endogenous transmission model (one in which economic interactions change the spread of the virus) differs from an exogenous transmission model (one in which the spread of the virus only depends on the number of susceptible and infected agents). This can also be thought of as the role of private mitigation. Second, I will explore the effect of various mitigation policies. In particular, I contrast a

\footnotetext{
${ }^{19}$ Sensitivity analysis in Section 5.1 reveals that assuming alternatively that all initial transmissions occur through consumption and labor activities is particularly promising in terms of generating infection and death dynamics that are consistent with current trajectories.

${ }^{20}$ The results are robust to a 30 percent reduction in the flow value of life, as discussed in Section 5.1.

${ }^{21}$ Section 5.1 shows that the main results are robust to assuming a 30 percent loss in efficiency.
} 
Table 2: Calibration of Epidemiological parameters

\begin{tabular}{lll}
\hline Parameters & Values & Targets / Source \\
\hline \hline Infection exit rate, $\pi_{X}$ & 0.78 & Expected infection duration: 18 days \\
Unconstrained death rate, & & Fatality rates in South Korea \\
$\delta_{1}^{u} \times 100$ & 0.09 & \\
$\delta_{2}^{u} \times 100$ & 0.94 & \\
$\delta_{3}^{u} \times 100$ & 8.47 & \\
Untreated death rate, $\delta_{j}^{c}$ & $2 \delta_{j}^{u}$ & Piguillem and Shi (2020) \\
Hospital capacity, $\kappa$ & 0.01 & See discussion above \\
Transmission parameters, & & Basic reproduction number, $R_{0}=2.2$, \\
consumption-related, $\beta_{c}$ & 0.08 & and initial transmission equally \\
labor-related, $\beta_{\ell}$ & 14.20 & likely through three channels \\
other, $\beta_{e}$ & 0.57 & \\
Flow value of infection $\hat{u}_{I}$ & -4.57 & 50 percent reduction in \\
& & flow utility value of average agent \\
Efficiency units $\eta_{j I}$ & $0.5 \eta_{j S}$ & See discussion above \\
\hline
\end{tabular}

stay-at-home order (lockdown policy), implemented in the model by imposing a maximum outside labor supply of 10 hours per week, with a stay-at-home subsidy (subsidy policy) that provides a subsidy for working less than 10 hours per week, funded by a tax on consumption. While both policies reduce infections and deaths, the subsidy policy delivers a higher welfare gain and is favored by all individuals in the economy, whereas the lockdown benefits older individuals at the expense of younger low-wage/low-wealth workers.

The economy starts in the pre-pandemic steady state in period $t=0$. Then, in period $t=1$ (March 27, 2020), the virus is introduced into the model so that 0.75 percent of the population is infected. ${ }^{22}$ I assume that a vaccine and cure is developed and fully implemented

\footnotetext{
${ }^{22}$ Due to the widely documented lack of testing in the US, I use the case fatality rates from South Korea and the number of deaths in the US to infer the number of infections in the US. In the US, there were 17,982 COVID-19 related deaths during the 14-day period from March 27, 2020, to April 9, 2020, according to https://www.worldometers.info/coronavirus/country/us/. Using the unconditional case fatality rate of 0.94 percent implied by the data from South Korea and the average infection duration of 18 days, this implies 2.5 million infections in the US as of March 27, or 0.75 percent of the population. None of the main results substantively change by starting with slightly fewer or more infections.
} 
in $t=\hat{t}$ (March 27, 2022); thereafter, the model transits back toward its original steady state. $^{23}$ An important caveat is that, while the steady state analysis was done in general equilibrium, the transition path analysis is done in partial equilibrium and efficiency wages and capital rental rates are fixed at their steady-state levels. ${ }^{24}$ I also do not require the government budget for retirement income to be balanced during the transition nor do I change the measure of newborns and their wealth distribution throughout the transition. This implies that, as a result of the pandemic, the measure of agents in the economy may be less than 1 during the transition. I provide a formal definition of the equilibrium with transition in Appendix B.

\subsection{Private mitigation}

To better understand the role of private mitigation, I contrast the baseline model-the "SIR Macro" model with endogenous transmission — with the alternative "SIR" model with exogenous transmission, where $\beta_{c}=\beta_{\ell}=0$. In the SIR model, I set $\beta_{e}=1.71$ so that the model has the same basic reproduction number, $R_{0}=2.2$, as in the baseline SIR Macro model.

Figure 1 shows that even though the SIR Macro and SIR models begin with the same reproduction number (panel a), the SIR Macro model exhibits a quicker decline in the reproduction number and consequently a lower number of infections (panel b) and deaths (panel c). This is because, in response to the pandemic, agents in the SIR Macro model reduce their consumption and outside hours dramatically, leading to a large decline in output, as can be seen in panels $(\mathrm{d})-(\mathrm{f})$.

Taking a closer look at the baseline model, consider the policy functions for consumption and outside labor of susceptible agents across the age, income, and wealth distribution

\footnotetext{
${ }^{23}$ While there is a lot of uncertainty regarding when a vaccine might be approved and distributed, this approach allows the computational burden to be reduced dramatically. An alternative approach would be to model the arrival of a vaccine and cure probabilistically. Sensitivity analysis in Section 5.1 reveals that assuming an earlier (but still deterministic) arrival of a vaccine and cure lowers the number of deaths, as expected, and results in an even stronger optimal mitigation policy.

${ }^{24}$ In conjunction with the assumption of a deterministic arrival of a vaccine and cure at $t=\hat{t}$, the partial equilibrium assumption implies that I do not need to solve for value and policy functions for $t \geq \hat{t}$, since even though the capital stock and distribution of agents evolve over a very long transition path, the prices and disease dynamics that are relevant for the household problem are constant for $t \geq \hat{t}$.
} 
Figure 1: Engodenous vs. exogenous transmission (no mitigation)

(a) Reproduction number

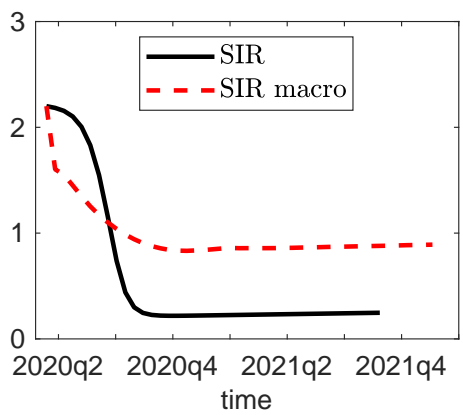

(d) Aggregate consumption

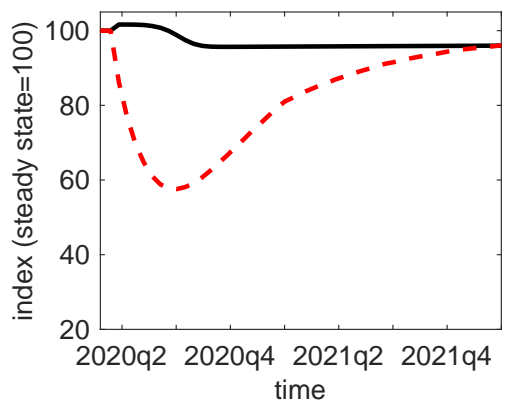

(b) Current infections

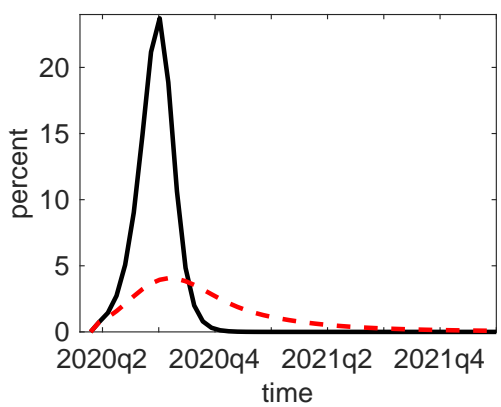

(e) Aggregate outside hours

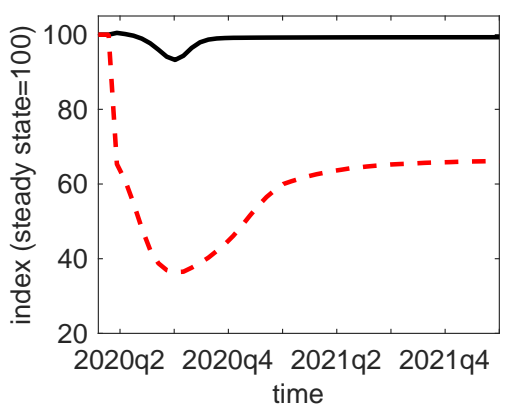

(c) Cumulative deaths

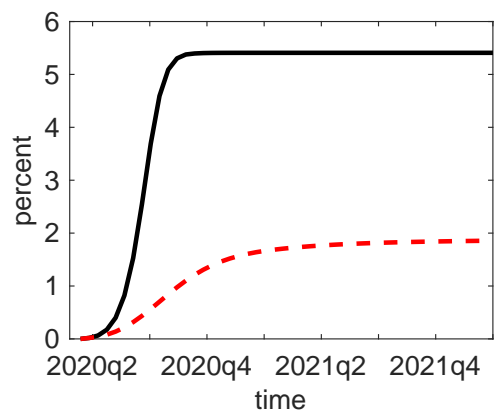

(f) Aggregate output

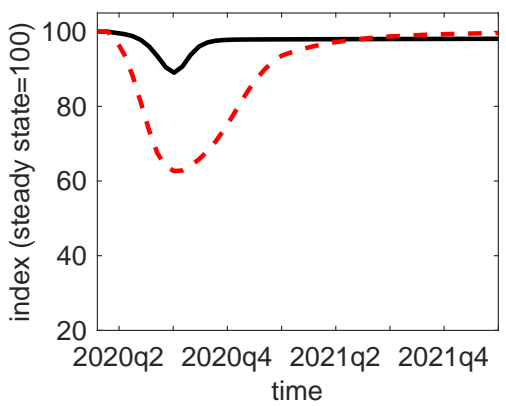

(Figure 2). The decline in consumption and outside hours is broad based. However, the decline in consumption is much greater for middle-aged and old agents than for young agents (panels a-c), and the declines in outside hours are much larger and more sustained for middleaged workers than for young workers (panels $\mathrm{d}-\mathrm{e}$ ). This reflects the lower fatality risk for young agents. Moreover, among young workers, the declines in consumption and outside hours are the smallest for low-wage/low-wealth workers. There are two reasons. First, while high-wage workers can switch to mostly working from home, low-wage workers are unable to do so. Second, low-wage/high-wealth workers sit out the labor market altogether during the infection peak, suggesting that the lack of precautionary savings prevents low-wage/lowwealth workers from reducing their labor supply by more. Overall, young workers experience a much larger increase in infections, as shown in panel (f).

\subsection{Mitigation policies}

The previous subsection highlighted the externalities at work: Young workers do not reduce their consumption and outside labor as much as their older counterparts and incur higher 
Figure 2: Response to pandemic (no mitigation)

(a) Consumption

(young, susceptible)

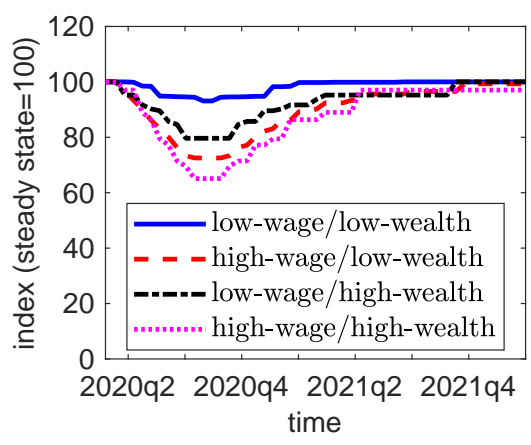

(d) Outside hours

(young, susceptible)

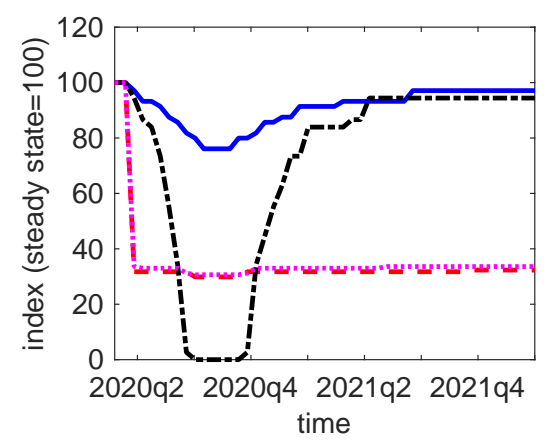

(b) Consumption

(middle, susceptible)

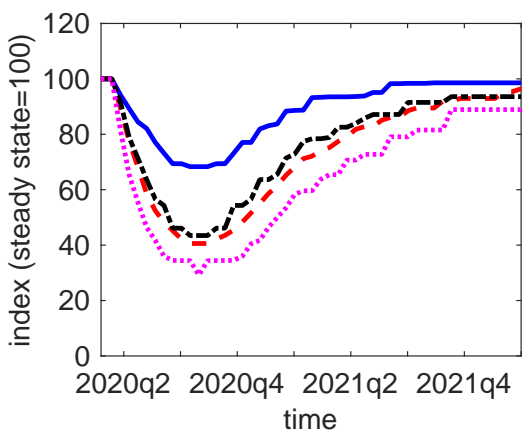

(e) Outside hours

(middle, susceptible)

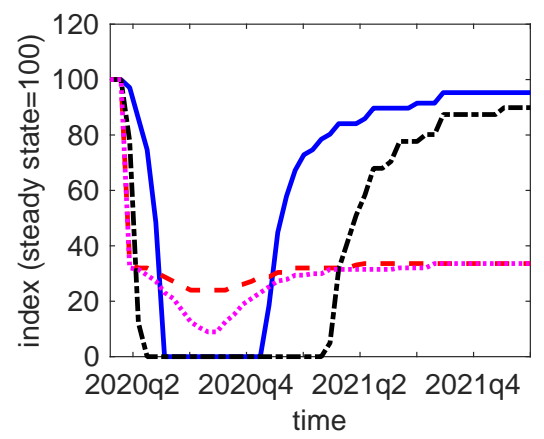

(c) Consumption

(old, susceptible)

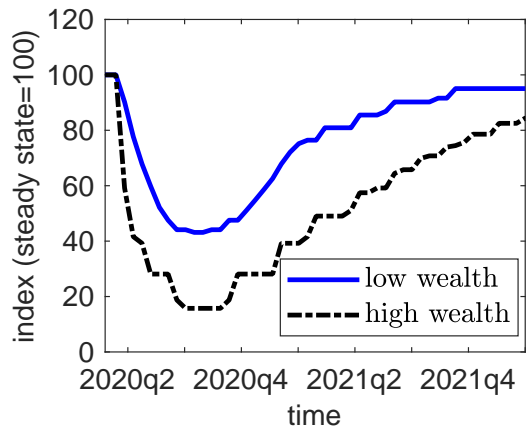

(f) Current infections

by age

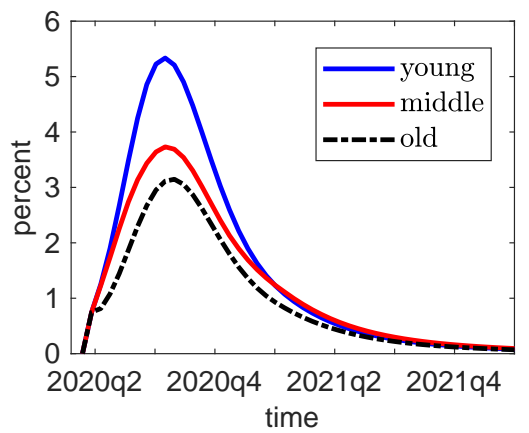

Notes: Low income and high income correspond to 10th and 90th percentiles of the steady state wage distribution, respectively. Low wealth and high wealth correspond to the 25 th and 75 th percentiles of the steady state wealth distribution, respectively. 
infections. These responses are individually rational in the sense that young workers do not face high fatality risk. However, higher rates of infection among young agents also lead to higher infections among older individuals, who face higher fatality rates.

In this subsection, I compare and contrast two different mitigation policies that reduce infection and death rates. The first is a stay-at-home order (lockdown policy), implemented in the model by restricting outside labor supply to less than $\bar{\ell}^{o}=0.1$, equivalent to 10 hours per week, beginning $t=1$ (March 27, 2020), and gradually phasing out after $t=\bar{t}$ (July 31, 2020). Specifically, the outside hours cap follows

$$
\bar{\ell}_{t}^{o}= \begin{cases}\bar{\ell}^{o} & \text { if } t<\bar{t} \\ \bar{\ell}^{o}\left(\frac{\hat{t}-t}{\hat{t}-\bar{t}}\right)^{2}+1-\left(\frac{\hat{t}-t}{\hat{t}-\bar{t}}\right)^{2} & \text { if } \bar{t} \leq t \leq \hat{t} \\ 1 & \text { otherwise }\end{cases}
$$

where $t=\hat{t}$ (March 25, 2022) is the date at which a vaccine and cure is developed and fully implemented. In equilibrium, the cap is no longer binding for any individual after October 9, 2020.

The second is a stay-at-home subsidy (subsidy policy), which incentivizes reduced work by providing a subsidy amount of $x=\$ 600$ per week for any working-age individual who works less than $\bar{\ell}=0.1$, equivalent to 10 hours per week. ${ }^{25}$ The subsidy begins at $t=1$ (March 27, 2020), with a gradual reduction after $t=\bar{t}$ (July 31, 2020). The time-varying subsidy amount follows

$$
x_{t}= \begin{cases}x & \text { if } t<\bar{t} \\ x\left(\frac{\hat{t}-t}{\hat{t}-\bar{t}}\right)^{2} & \text { if } \bar{t} \leq t \leq \hat{t} \\ 0 & \text { otherwise }\end{cases}
$$

The subsidy declines to $\$ 300$ by January 15, 2021, and to zero by $t=\hat{t}$ (March 27, 2022). The subsidy is funded by an 18 percent consumption tax, which begins at $t=1$ (March 27, 2020) and gradually phases out after $t=\bar{t}$ (July 31, 2020), following a similar path to the

\footnotetext{
${ }^{25}$ Here, I assume that, for administrative purposes, the criteria to qualify for the subsidy is for total hours worked as it may be difficult for the administrator to ascertain what fraction of hours were outside versus at home. This is in contrast to the lockdown policy, where I assume that the hours cap is for outside labor. The idea is that the lockdown is administered at the firm-level whereas the subsidy is administered at the individual-level.
} 
Figure 3: Disease transmission and aggregates (with and without mitigation)

(a) Reproduction number

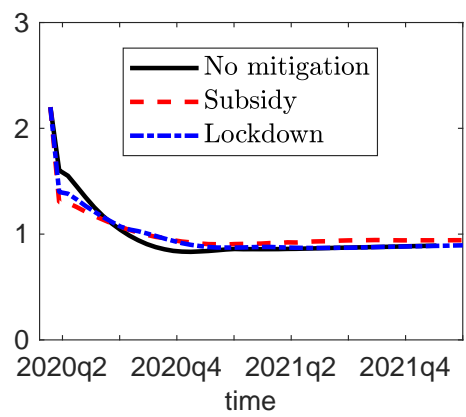

(d) Aggregate consumption

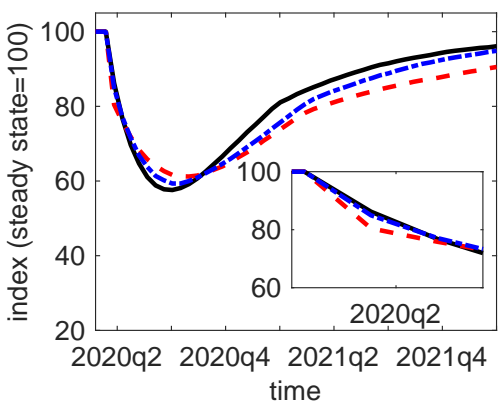

(b) Current infections

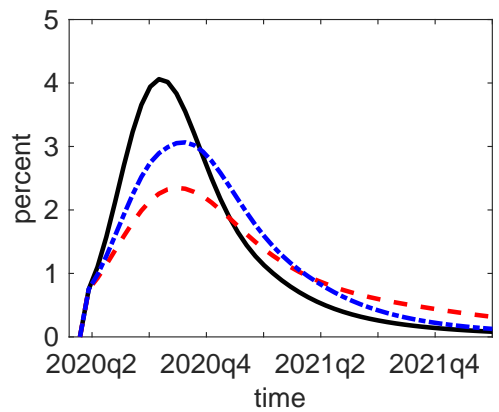

(e) Aggregate outside hours

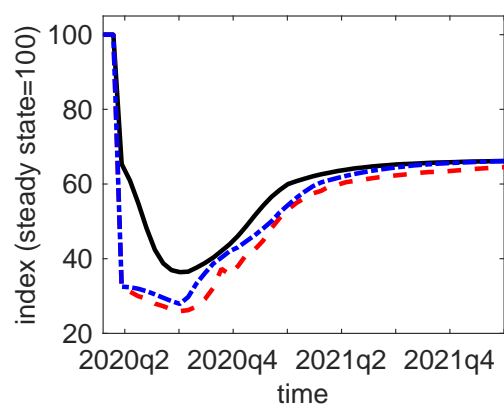

(c) Cumulative deaths

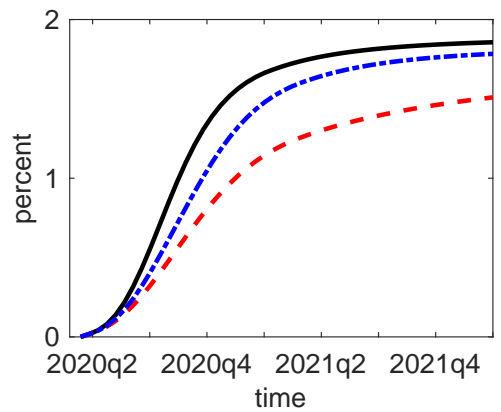

(f) Aggregate output

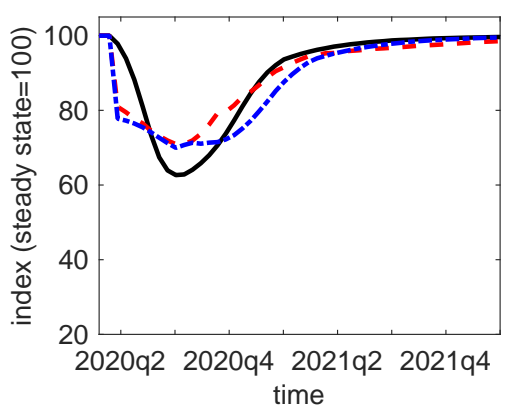

subsidy amount. The tax and subsidy do not clear period-by-period, but rather they clear in net present value. Thus, both mitigation policies are budget neutral from the government's perspective.

Figure 3 panels (a)-(c) plot the evolution of the disease under the laissez-faire scenario as well as the two mitigation scenarios. Relative to the case with no mitigation, both mitigation policies reduce the reproduction number faster, leading to a lower peak in infection rates and fewer deaths. However, the subsidy policy more effectively reduces the number of deaths than the lockdown. This is because, as shown in panels (d)-(e), the subsidy policy generates a sharper initial decline in consumption and a more sustained decline in outside hours. Finally, as can be seen in panel (f), both mitigation policies induce a sharp reduction in output initially but avoid the larger reductions in output that occur during the peak in infections in the no-mitigation scenario.

Figure 4 panels (a)-(c) and (d)-(e) show the policy functions for consumption and outside hours, respectively, for susceptible individuals under the subsidy policy. ${ }^{26}$ Relative to the

\footnotetext{
${ }^{26}$ The analogous figure for the lockdown can be found in Appendix D.
} 
Figure 4: Response to pandemic (stay-at-home subsidy)

(a) Consumption

(young, susceptible)

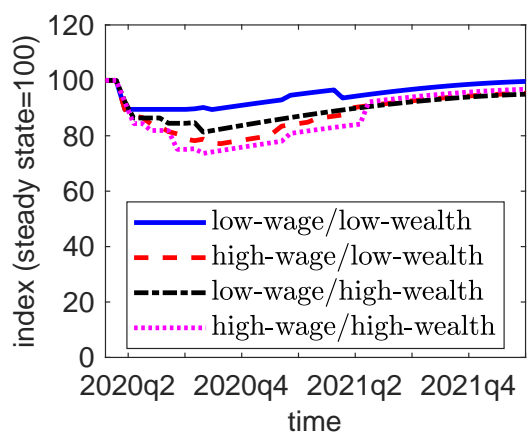

(d) Outside hours

(young, susceptible)

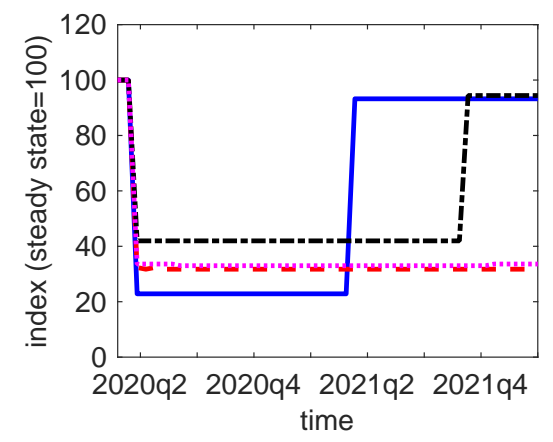

(b) Consumption

(middle, susceptible)

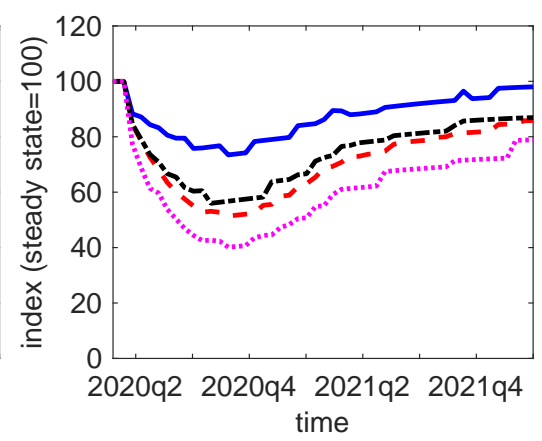

(e) Outside hours

(middle, susceptible)

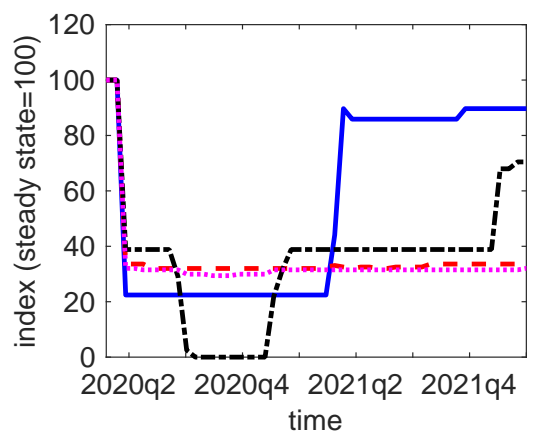

(c) Consumption

(old, susceptible)

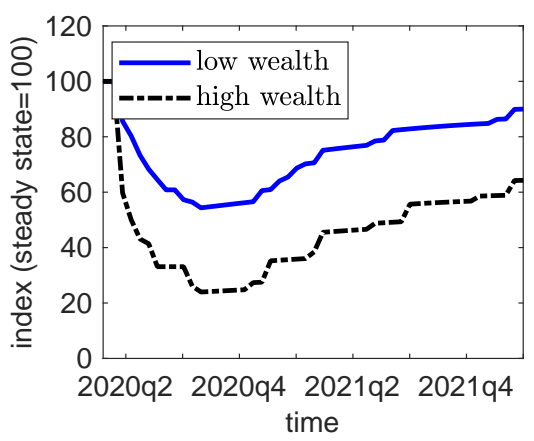

(f) Current infections

by age

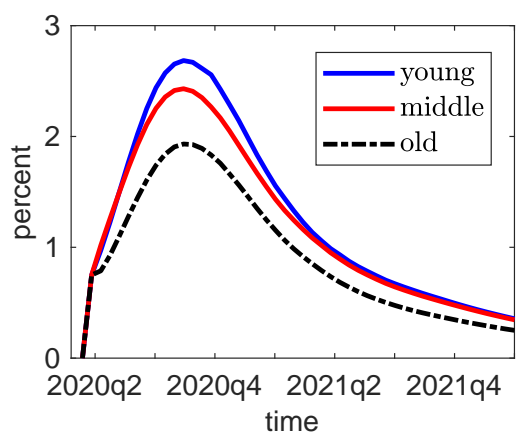

Notes: Low and high wage correspond to 10th and 90th percentiles of the steady state wage distribution, respectively. Low and high wealth correspond to the 25 th and 75 th percentiles of the steady state wealth distribution, respectively.

case with no mitigation, the reduction in consumption and outside hours is more broadbased, including declines in consumption and hours for young low-wage/low-wealth workers. As a result, the peak infection rate for young agents declines from 5.3 percent to 2.7 percent (panel f). Notice that, relative to the case with no mitigation, the decline in outside hours for young low-wage/low-wealth workers is entirely due to the subsidy, whereas the decline in outside hours for young high-wage workers is little changed, and if anything, a little bit smaller due to the lower infection risk under the subsidy policy. Furthermore, the decline in outside hours for high-wage workers reflects a shift to a larger share of work performed at home, and does not qualify them for the subsidy.

Qualitatively, the lockdown policy has similar properties as the subsidy policy in the 
sense that they both reduce consumption and outside labor, resulting in fewer infections and deaths. However, in terms of welfare, measured in consumption equivalents, the lockdown policy is vastly inferior. ${ }^{27}$ The subsidy policy reduces the average welfare loss from the pandemic by 2.4 percentage points, whereas the lockdown policy reduces the average welfare loss by only 0.2 percentage points, as can be seen in Table 3 . This is because the lockdown policy is mainly favored by older agents who most value the lower risk of death induced by the policy and is opposed by younger, low-wage/low-wealth workers for whom the lockdown policy is most binding. Overall, the lockdown policy is favored by only 73.6 percent of the initial population. In contrast, the subsidy policy is favored by all individuals in the economy, making it a Pareto improvement relative to no mitigation.

The stay-at-home order and stay-at-home subsidy policies are meant to resemble the state-level stay-at-home orders and parts of the Coronavirus Aid, Relief, and Economic Security (CARES) Act, such as the Pandemic Unemployment Assistance (PUA), which provided an additional $\$ 600$ per week for unemployed individuals, and the Paycheck Protection Program (PPP), which provided funds to small businesses to pay furloughed workers. However, there are some notable differences. First, while the timing of the subsidy policy is fairly consistent with the PUA, which became effective March 27, 2020, and expired July 31, 2020; it is less so for the lockdown. The stay-at-home orders began in most states between March 23 and April 1, but the duration and intensity varied substantially across states and many began reopening in early May. ${ }^{28}$ Second, while the PUA subsidy requires involuntary unemployment or underemployment, the subsidy studied in this model is based on voluntary reductions in hours worked. Third, the stay-at-home orders affected workers differently based on whether or not their place of work was essential (grocery stores) or social-intensive (restaurants and bars). By abstracting from sectors and occupations, the model cannot speak directly to these differences. However, to the extent that social-intensive occupations tend to have lower wages as documented by Kaplan et al. (2020), the model indirectly captures these differences since the lockdown disproportionately affects lower-wage individuals. Finally, the model subsidy is funded by a consumption tax, whereas the PUA subsidy is debt-financed. I chose the consumption tax for two reasons. First, it reduces the incentive

\footnotetext{
${ }^{27}$ Specifically, the consumption equivalent is defined as the percentage change of remaining lifetime consumption in the steady state that would make the individual indifferent to the pandemic and, if applicable, mitigation policies.

${ }^{28}$ See Moreland et al. (2020) for an analysis of stay-at-home orders across states.
} 
Table 3: Welfare consequences of pandemic and mitigation policies

\begin{tabular}{|c|c|c|c|c|c|c|c|c|}
\hline \multirow{3}{*}{$\begin{array}{l}\text { wealth } \\
\text { wage }\end{array}$} & \multicolumn{5}{|c|}{ consumption equivalents (percent) } & \multirow{3}{*}{$\begin{array}{c}\text { policy } \\
\text { support } \\
\text { (percent) }\end{array}$} & \multirow{3}{*}{$\begin{array}{l}\text { 2-year } \\
\text { output } \\
\text { (index) }\end{array}$} & \multirow{3}{*}{$\begin{array}{l}\text { deaths } \\
\text { (percent) }\end{array}$} \\
\hline & \multicolumn{2}{|c|}{ low } & \multicolumn{2}{|c|}{ high } & \multirow{2}{*}{ average } & & & \\
\hline & low & high & low & high & & & & \\
\hline no mitigation & & & & & -19.6 & & 90.2 & 1.9 \\
\hline young & -2.6 & -3.6 & -3.8 & -4.7 & & & & \\
\hline middle & -11.4 & -14.7 & -15.2 & -20.4 & & & & \\
\hline old & -30 & 0.3 & -4 & & & & & \\
\hline stay-at-home subsic & & & & & -17.2 & 100.0 & 89.8 & 1.5 \\
\hline young & -2.2 & -3.5 & -3.2 & -4.4 & & & & \\
\hline middle & -9.1 & -12.5 & -13.0 & -18.0 & & & & \\
\hline old & -2 & 6.3 & -41 & & & & & \\
\hline stay-at-home order & & & & & -19.4 & 73.6 & 88.6 & 1.8 \\
\hline young & -4.3 & -3.7 & -3.8 & -4.6 & & & & \\
\hline middle & -11.8 & -14.5 & -15.0 & -20.1 & & & & \\
\hline old & -2 & 9.3 & -4 & & & & & \\
\hline
\end{tabular}

Notes: Low and high wage correspond to below and above the median wage, respectively. Low and high wealth corresponds to below and above the median wealth, respectively. Blue and red colors denote groups with welfare gains and losses from the mitigation policies, respectively. Policy support refers to the percent of the initial population that benefits from the mitigation policy. Output refers to output from $t=1$ (March $27,2020)$ to $t=52$ (March 24, 2022), compared with the analogous 52-period output in the steady state, indexed at 100 . 
to engage in consumption activities, another way in which the virus transmits. Second, in contrast to debt-financing, which typically imposes a disproportionately larger burden on young individuals, the burden of the consumption tax is more widely shared. To the extent that older individuals stand to gain the most from the mitigation policies, this is a desirable feature. Despite these differences, for expositional purposes, I refer to US policy as the implementation of both the subsidy and lockdown policies.

At the time of writing, Congress has yet to agree on an appropriate extension of the CARES Act, which expired on July 31, 2020. While the policies studied in this subsection were designed to resemble some of the policies that were previously implemented, I now discuss the properties of optimal mitigation policies in the next section.

\section{$5 \quad$ Optimal mitigation policies}

I investigate the properties of optimal mitigation policies over a limited set of policy instruments. In particular, I solve for the transition paths for 1,600 combinations of policy parameters, in which the weekly subsidy amount, $x$, varies from $\$ 0$ to $\$ 1,800$, the duration varies from 2 to 22 months (by adjusting $\bar{t}$ ), and the hours threshold to qualify for the subsidy, $\bar{\ell}$, varies from 0 to 10 weekly hours, with and without a lockdown (by adjusting $\bar{\ell}^{o}$ ). In all cases with a positive subsidy, I solve for a consumption tax that clears the government budget constraint in present value, making all configurations budget-neutral. The policies are assumed to gradually phase out according to the functional forms specified in equations (24) and (25). All other parameters are kept the same as in the previous subsection.

Figure 5 plots the effects of varying subsidy amounts and duration, where the hours threshold, $\bar{\ell}$, is fixed at 0 and there is no lockdown. Panel (a) shows that average welfare is increasing in both the subsidy amount and duration, and panel (b) shows that for moderate subsidy amounts, support for the mitigation policy is unanimous. Falling support for the policy is due to the higher consumption tax rate associated with larger subsidy amounts and

longer durations (panel e). Panel (c) demonstrates that deaths are decreasing in both the subsidy amount and duration. Interestingly, the effects of the subsidy amount on output are nonmonotonic (panel d). In particular, for moderate subsidy amounts, the mitigation policy actually increases output relative to the case with no mitigation. This is due to two opposing effects. On the one hand, larger subsidies induce increasingly productive workers to reduce 
their hours, reducing aggregate productivity and output. This is the direct (selection) effect. On the other hand, larger subsidies induce lower economic activities, causing a decline in the severity of the infection peak. This reduces the infection and fatality risk, and thus makes it safer to engage in more economic activities. This is the indirect (public health) effect. At moderate subsidy amounts, the direct effect is small because the subsidy only induces low-wage workers to reduce their hours, and thus, the indirect effect can dominate the direct effect, leading to an increase in output relative to the no-mitigation scenario.

Next, I investigate the effects of changing the hours threshold that determines the eligibility for receiving a subsidy and the effects of implementing a lockdown, where the subsidy amount and duration are fixed at $\$ 900$ and 18 months, respectively (Figure 6). Panel (a) shows that average welfare is slightly higher with a lockdown and is relatively unchanged with respect to the hours threshold. Lockdowns and positive hours thresholds, however, are not supported unanimously, as seen in panel (b). This is because lockdowns and positive hours thresholds increase the consumption tax rate (panel e) and reduce output (panel d), while only slightly reducing deaths (panel c). Lockdowns reduce output because they induce a negative selection effect: they reduce the labor supply of medium-wage workers by more than the low-wage workers who have already reduced their labor supply to qualify for the subsidy (high-wage workers are unaffected by the lockdown as they are mostly working from home). Larger hours thresholds also reduce output through a negative selection effect: They increase the labor supply of low-wage workers who can work increasingly more hours and still qualify for the subsidy but reduce the labor supply of increasingly more productive workers who may find it worthwhile to reduce their hours and qualify for the subsidy. The net effect on outside hours worked is ambiguous, leading to very little changes in deaths.

Mitigation policies have often been portrayed in the context of a tradeoff between output and health. Figure 7 provides a scatter plot of the two-year output and COVID-19-related deaths for all of the policy parameter configurations. We can see that for large reductions in deaths, there is indeed a tradeoff between output and saving lives. However, we can also see that there are plenty of policy configurations that simultaneously increase output and save more lives relative to the no mitigation case. As reference points, I include the constrained optimum, which maximizes welfare conditional on full support; the output maximizing configuration; and the configuration that most closely resembles US policy. The policy parameters of each configuration is summarized in Table 4. Relative to the configura- 
Figure 5: Effects of subsidy amount and duration
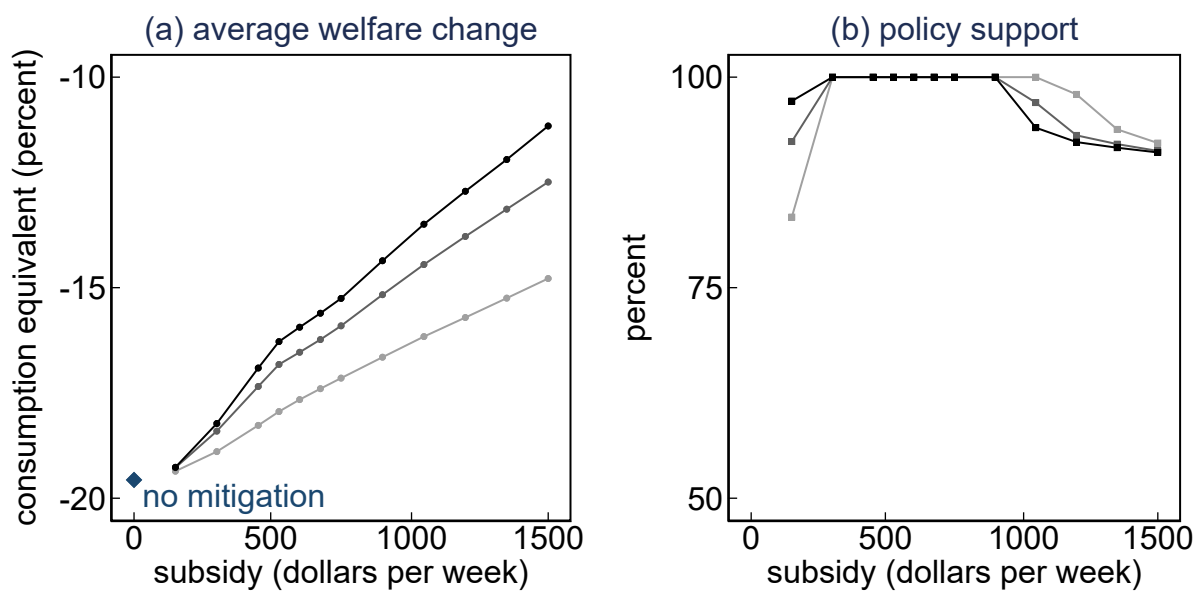

(c) deaths

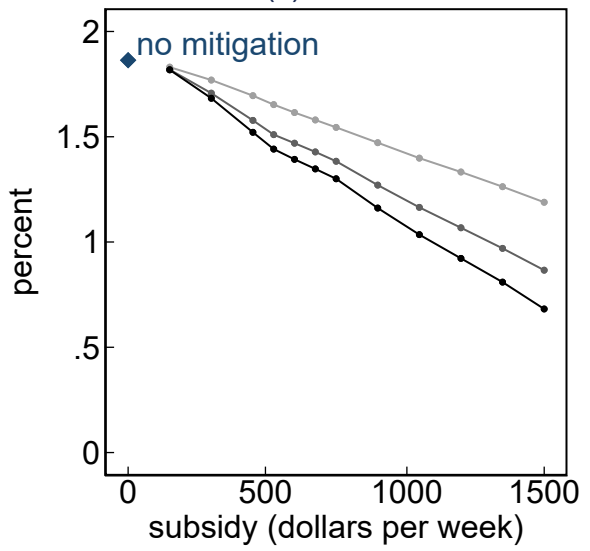

(d) output

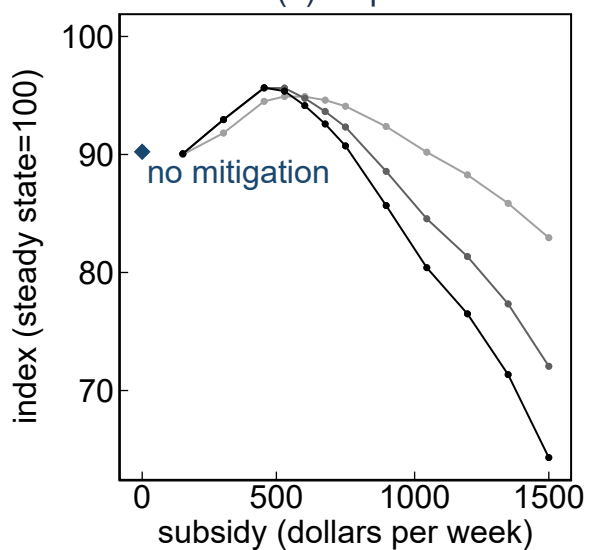

(e) consumption tax rate
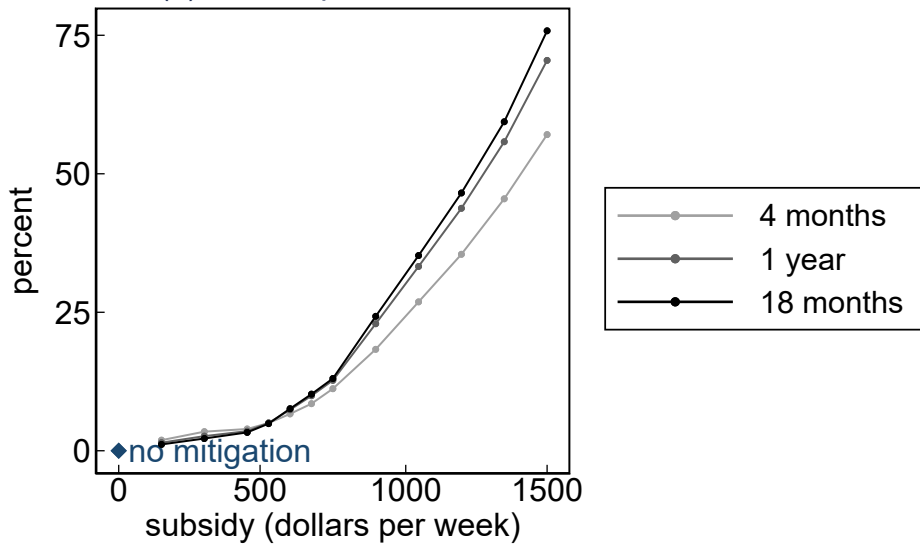

Notes: The graphs show the effects of varying subsidy amounts and duration, with the hours threshold, $\bar{\ell}$, equal to 0 and no lockdown. Average welfare change reports the population-weighted average of individual consumption equivalents. Policy support refers to the percent of the initial population that gains from the mitigation policy. Output refers to output from $t=1$ (March 27, 2020) to $t=52$ (March 24, 2022), compared to the analogous 52 -period output in the steady state, indexed at 100. 
Figure 6: Effects of hours threshold and lockdown
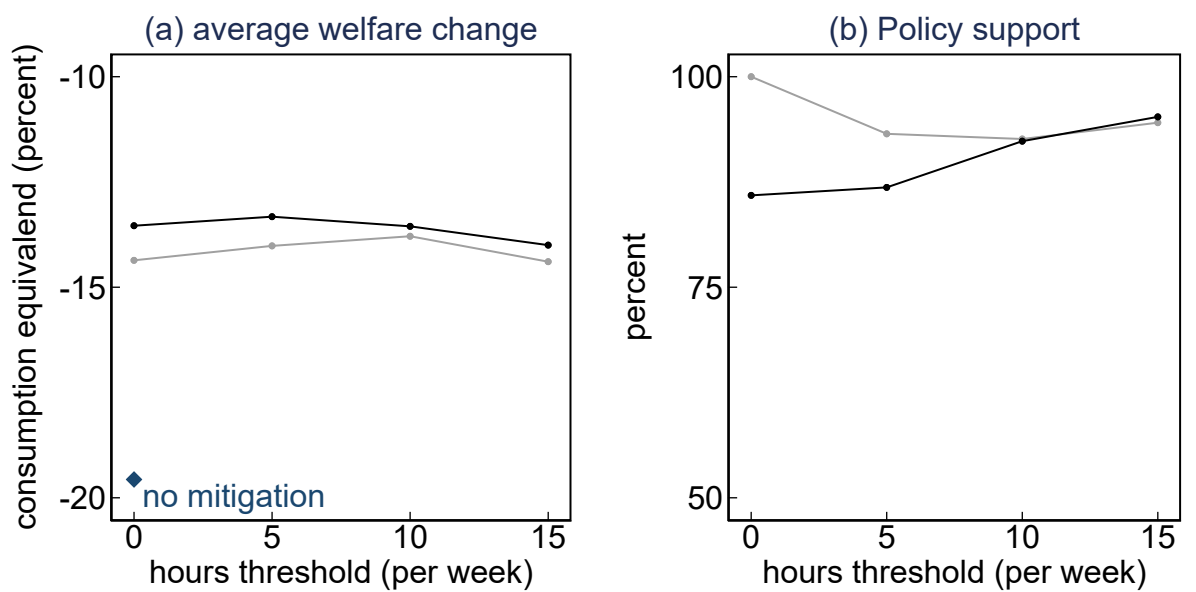

(c) deaths

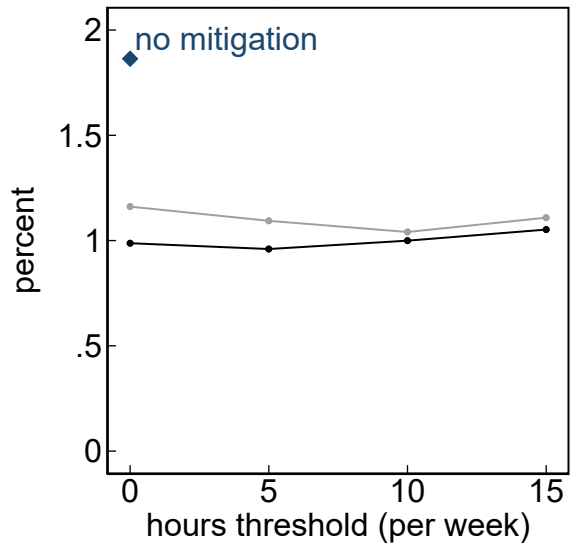

(d) output

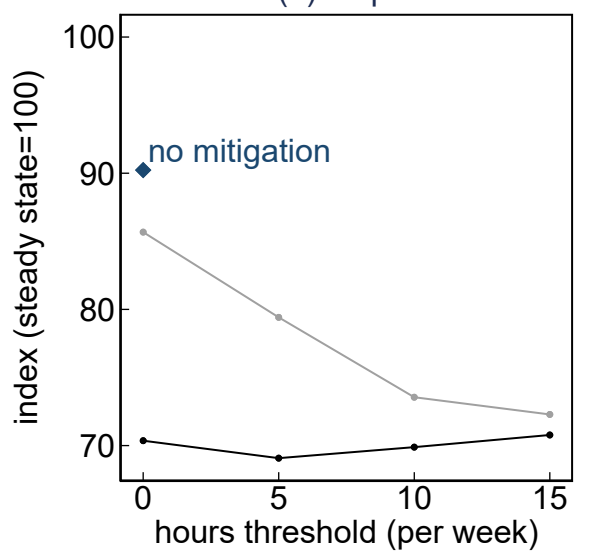

(e) consumption tax rate
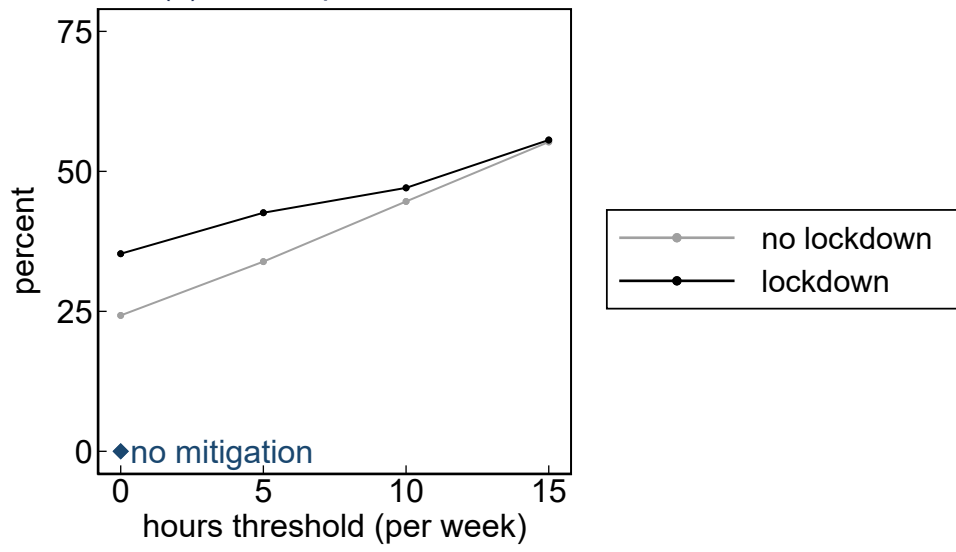

Notes: The graphs show the effects of varying hours thresholds with and without lockdown, where the subsidy amount and duration is fixed at $\$ 900$ and 18 months, respectively. Average welfare change reports the population-weighted average of individual consumption equivalents. Policy support refers to the percent of the initial population that gains from the mitigation policy. Output refers to output from $t=1$ (March $27,2020)$ to $t=52$ (March 24, 2022), compared with the analogous 52-period output in the steady state, indexed at 100 . 
Figure 7: Output and lives

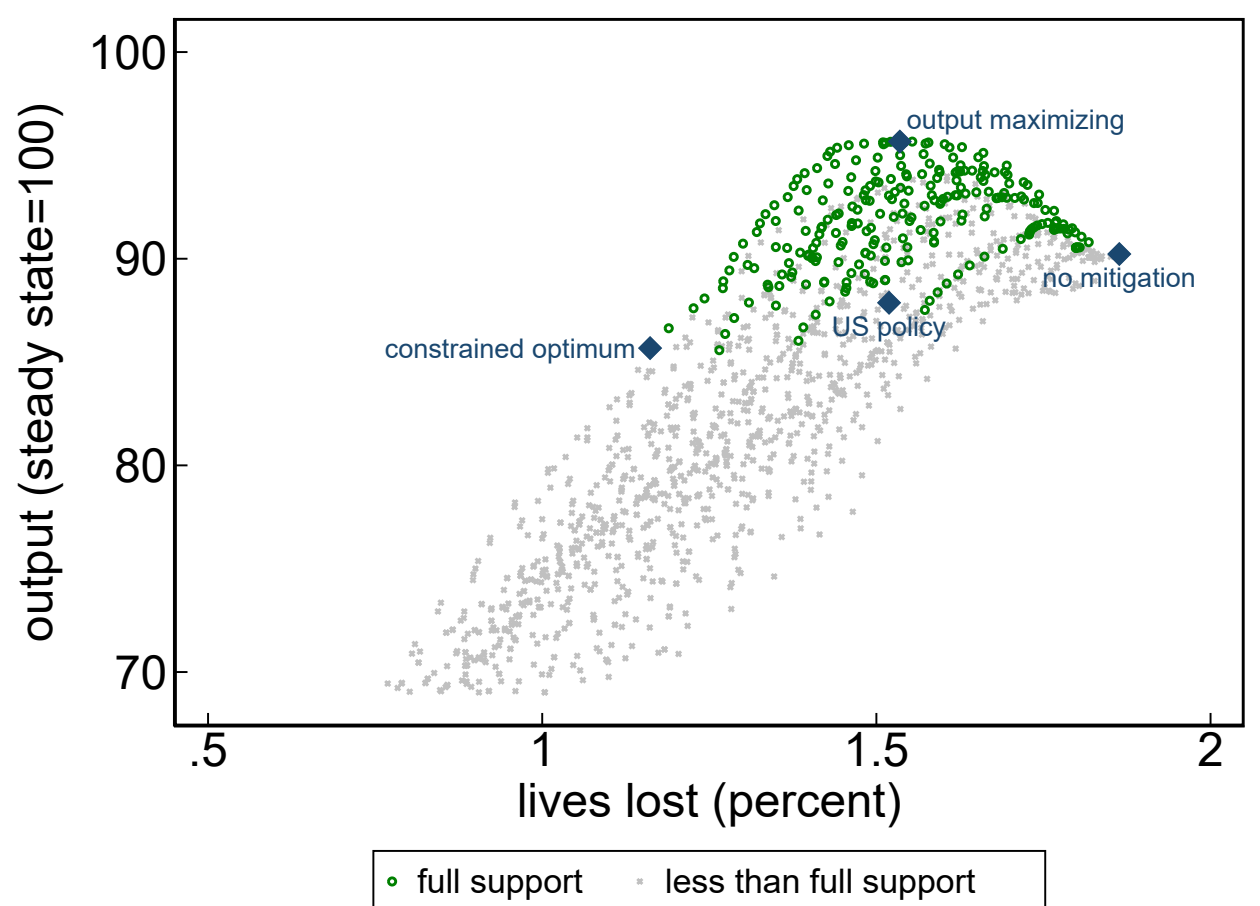

Notes: Output refers to output from $t=1$ (March 27, 2020) to $t=52$ (March 24, 2022), compared to the analogous 52-period output in the steady state. Full support refers to Pareto improvements relative to no mitigation.

tion that most resembles current US policy, Figure 7 shows that extending the duration of the subsidy (from 4 to 18 months) and increasing the subsidy amount (from $\$ 600$ to $\$ 900$ per week) can lead to a substantially larger reduction in deaths without significantly changing the level of output. Similarly, extending the duration of the subsidy (from 4 to 16 months) and decreasing the subsidy amount (from $\$ 600$ to $\$ 450$ per week) can substantially increase output without a large change in deaths. Neither policy features a lockdown or a positive hours threshold.

Figure 8 shows the aggregate dynamics under the configuration that resembles US policy, the constrained optimum, and the output maximizing policy. Both US policy and the constrained optimal policy are initially effective in curbing infections and deaths relative to the output maximizing policy and to no mitigation, as can be seen in panels (a)-(c). However, in the case of US policy, the premature termination of mitigation efforts eventually 
Table 4: Policy configurations

\begin{tabular}{|c|c|c|c|c|c|c|c|}
\hline & $\begin{array}{l}\text { subsidy } \\
\text { amount } \\
(\$ / \text { week })\end{array}$ & $\begin{array}{l}\text { duration } \\
\text { (months) }\end{array}$ & $\begin{array}{l}\text { threshold } \\
\text { (hours } \\
\text { /week) }\end{array}$ & $\begin{array}{l}\text { lock- } \\
\text { down }\end{array}$ & $\begin{array}{l}\text { average } \\
\text { welfare } \\
\text { change } \\
\text { (percent) }\end{array}$ & $\begin{array}{l}\text { 2-year } \\
\text { output } \\
\text { (index) }\end{array}$ & $\begin{array}{c}\text { deaths } \\
\text { (percent) }\end{array}$ \\
\hline constrained optimum* & 900 & 18 & 0 & no & -14.4 & 85.7 & 1.2 \\
\hline output maximizing* & 450 & 16 & 0 & no & -17.0 & 95.7 & 1.5 \\
\hline US policy & 600 & 4 & 10 & yes & -17.2 & 87.9 & 1.5 \\
\hline no mitigation & 0 & 0 & none & no & -19.6 & 90.2 & 1.9 \\
\hline
\end{tabular}

Notes: Average welfare change reports the population-weighted average of individual consumption equivalents. Output refers to output from $t=1$ (March 27, 2020) to $t=52$ (March 24, 2022), relative to the analogous 52-period output in the steady state, indexed at 100. * denotes Pareto improvements relative to the no mitigation case.

results in a similar number of deaths to that in the output maximizing policy, even with a much larger reduction in output (panels c and f). Notice that US policy not only induces an initially larger decline in output due to stronger mitigation efforts (larger subsidy and lockdown) relative to the output maximizing policy, but also causes lower output throughout the transition (panel f). The lower output in 2021 is entirely due to private mitigation in response to the more severe pandemic induced by the premature termination of mitigation policies.

Finally, notice that the model with US policy produces a path with death rates that are higher than in the data, even when one considers excess deaths. Sensitivity analyses in the next subsection reveals that assuming that the virus transmits only through economic channels (consumption and labor) is particularly promising in matching the current progression of the virus in the US. Importantly, I show that the main policy implications are robust to this and numerous other changes to model parameters and assumptions.

\section{$5.1 \quad$ Robustness}

In this subsection, I explore the robustness of the results to alternative parameter and modeling choices. I find that although the level of average welfare, deaths, and output can vary substantially, the main policy implications are extremely robust. Under all alternative configurations, the constrained optimal policies involve larger subsidies and longer durations 
Figure 8: Disease transmission and aggregates (optimal policies)

(a) Reproduction number

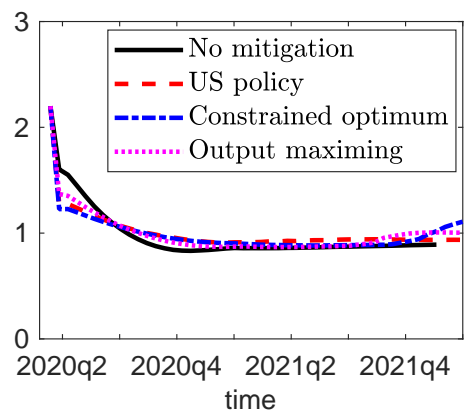

(d) Aggregate consumption

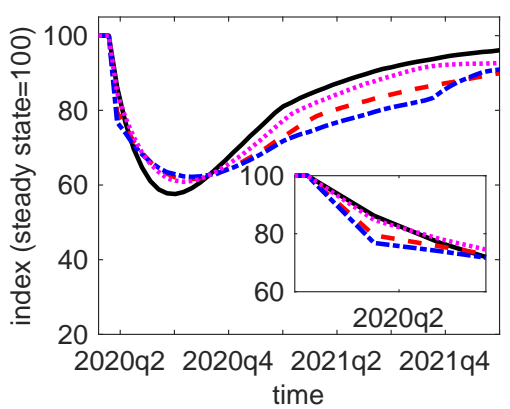

(b) Current infections

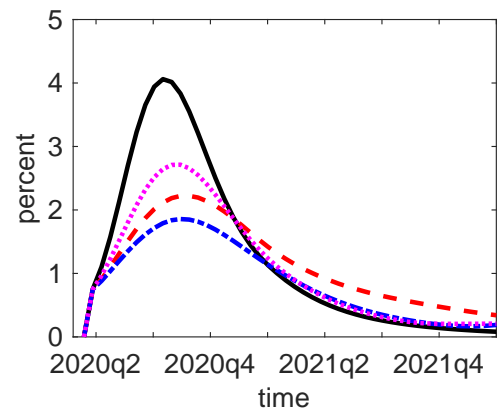

(e) Aggregate outside hours

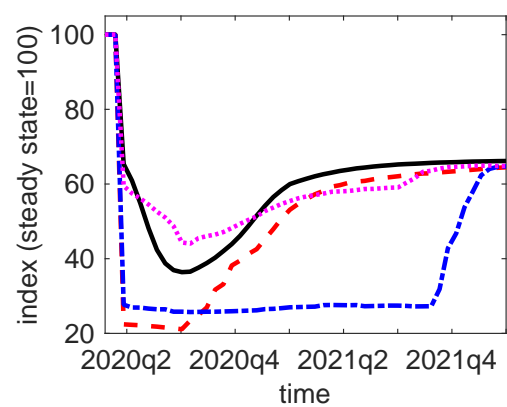

(c) Cumulative deaths

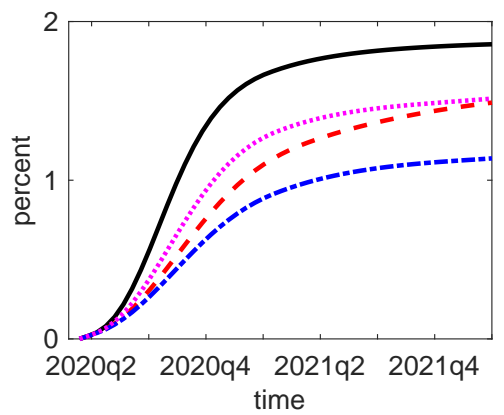

(f) Aggregate output

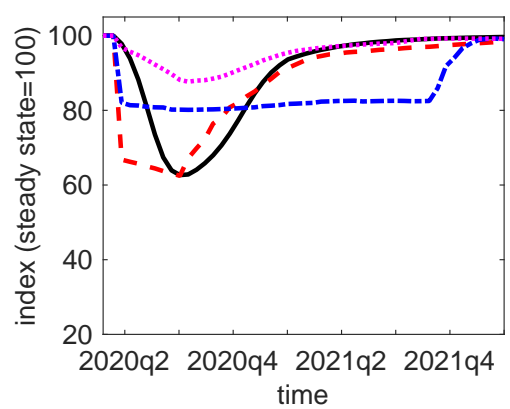

than US policy and the output maximizing policies involve weakly smaller subsidies and longer durations than US policy. Furthermore, the result that both constrained optimal and output maximizing policies involve no lockdown and a zero-hour threshold is robust to all alternative configurations. Finally, in each configuration, the output maximizing policy leads to lower deaths and higher output than without mitigation. The policy parameters of the constrained optimal and output maximizing policies under alternative parameter values and modeling choices are summarized in Tables 5-6.

Lower value of statistical life. In the baseline calibration, I use a VSL of $\$ 11.5$ million, which corresponds to 7,475 biweekly consumption per capita. As a robustness check, I use an alternative VSL recommended in U.S. Environmental Protection Agency (2020), \$7.4 million in 2006 dollars, or 6,208 times biweekly consumption per capita in 2006. By comparing the no mitigation results in Tables 4 and 5, I find that assigning a lower value of statistical life leads to slightly higher deaths and output and a smaller welfare loss as result of the pandemic. The main policy implications, however, remain the same: The constrained optimal policy involves a larger and longer duration subsidy than US policy and the output maximizing 
policy also involves a lower but longer duration subsidy than US policy. Both configurations feature no lockdowns and a zero-hour threshold for qualifying for the subsidy.

Smaller utility loss during infection. I also consider a 30 percent reduction in the flow value of life during infection and compare the results to the 50 percent reduction studied in the baseline. The no mitigation scenarios are nearly identical and the main policy implications are also nearly unchanged. I conclude that the utility loss during infection is not a main driver of the economic or epidemiological dynamics.

Smaller efficiency loss during infection. Next, I consider a 30 percent reduction in labor efficiency during infection, compared with the baseline calibration of a 50 percent reduction. Interestingly, comparing the no mitigation scenarios under a 30 percent versus a 50 percent efficiency reduction during infection reveals that welfare and output is actually lower under the 30 percent reduction. This is because the smaller efficiency loss for infected individuals induce these infected individuals to work more, increasing the infection risk of susceptible agents, leading to a decline in hours worked among susceptible agents. The main policy implications are nevertheless unchanged, except that the output maximizing policy involves the same size subsidy as US policy but for a longer duration.

Larger hospital capacity. I also investigate the implications of a larger hospital capacity of 1.5 percent. As expected, this leads to fewer deaths and a smaller welfare loss under the no mitigation scenario, compared with the baseline calibration. Nevertheless, the policy prescriptions remain nearly identical.

Earlier vaccine. In the baseline calibration, I assume that a vaccine and cure is developed and implemented two years after the introduction of the virus. As can be seen in the fifth panel of Table 5, assuming an earlier arrival of a vaccine and cure leads to lower deaths and a smaller welfare loss. The main policy prescriptions are robust to this alternative assumption. In fact, we can see that the constrained optimal response is much stronger, prescribing a much larger subsidy $(\$ 1,800)$, leading to a dramatic decline in both output and deaths. This is also consistent with the finding in Glover et al. (2020) that deeper and longer mitigation policies are preferred with an earlier vaccine arrival. 
Table 5: Sensitivity analysis

\begin{tabular}{|c|c|c|c|c|c|c|c|}
\hline & $\begin{array}{l}\text { subsidy } \\
\text { amount } \\
(\$ / \text { week })\end{array}$ & $\begin{array}{l}\text { duration } \\
\text { (months) }\end{array}$ & $\begin{array}{l}\text { threshold } \\
\text { (hours } \\
\text { /week) }\end{array}$ & $\begin{array}{l}\text { lock- } \\
\text { down }\end{array}$ & $\begin{array}{l}\text { average } \\
\text { welfare } \\
\text { change } \\
\text { (percent) }\end{array}$ & $\begin{array}{l}\text { 2-year } \\
\text { output } \\
\text { (index) }\end{array}$ & $\begin{array}{c}\text { deaths } \\
\text { (percent) }\end{array}$ \\
\hline \multicolumn{8}{|c|}{ lower value of statistical life $(V S L=6208 \bar{c})$} \\
\hline constrained optimum* & 750 & 22 & 0 & no & -13.7 & 89.5 & 1.4 \\
\hline output maximizing* & 450 & 14 & 0 & no & -15.5 & 96.1 & 1.6 \\
\hline US policy & 600 & 4 & 10 & yes & -15.6 & 88.5 & 1.6 \\
\hline no mitigation & 0 & 0 & none & no & -17.7 & 91.4 & 2.0 \\
\hline \multicolumn{8}{|c|}{ smaller utility loss during infection $(\hat{u}=-2.74)$} \\
\hline constrained optimum* & 750 & 22 & 0 & no & -15.0 & 89.5 & 1.3 \\
\hline output maximizing* & 450 & 14 & 0 & no & -17.0 & 95.8 & 1.6 \\
\hline US policy & 600 & 4 & 10 & yes & -17.1 & 88.1 & 1.5 \\
\hline no mitigation & 0 & 0 & none & no & -19.4 & 90.6 & 1.9 \\
\hline \multicolumn{8}{|c|}{ smaller efficiency loss during infection $\left(\eta_{j I}=0.7 \eta_{j S}\right)$} \\
\hline constrained optimum* & 750 & 22 & 0 & no & -15.6 & 86.8 & 1.3 \\
\hline output maximizing* & 600 & 10 & 0 & no & -17.6 & 91.4 & 1.6 \\
\hline US policy & 600 & 4 & 10 & yes & -17.8 & 86.1 & 1.6 \\
\hline no mitigation & 0 & 0 & none & no & -19.8 & 89.5 & 1.9 \\
\hline \multicolumn{8}{|c|}{ larger hospital capacity $(\kappa=0.015)$} \\
\hline constrained optimum* & 900 & 18 & 0 & no & -13.3 & 85.7 & 1.0 \\
\hline output maximizing* & 450 & 14 & 0 & no & -16.1 & 96.0 & 1.4 \\
\hline US policy & 600 & 4 & 10 & yes & -16.0 & 88.4 & 1.4 \\
\hline no mitigation & 0 & 0 & none & no & -18.6 & 90.1 & 1.7 \\
\hline \multicolumn{8}{|c|}{ earlier vaccine $(\hat{t}=27$, March 26, 2021) } \\
\hline constrained optimum* & 1800 & 10 & 0 & no & -7.5 & 76.9 & 0.4 \\
\hline output maximizing* & 525 & 12 & 0 & no & -14.4 & 96.7 & 1.2 \\
\hline US policy & 600 & 4 & 10 & yes & -15.3 & 88.5 & 1.3 \\
\hline no mitigation & 0 & 0 & none & no & -18.5 & 90.4 & 1.7 \\
\hline
\end{tabular}

Notes: Average welfare change reports the population-weighted average of individual consumption equivalents. Output refers to output from $t=1$ (March 27, 2020) to $t=52$ (March 24, 2022), compared with the analogous 52-period output in the steady state, indexed at 100. * denotes Pareto improvements relative to the no mitigation case. 
Higher basic reproduction number. I also investigate the implications of assuming a higher basic reproduction number of 2.5, compared to the baseline value of 2.2. As expected, a higher basic reproduction number leads to a larger number of deaths, as shown in the first panel of Table 6. The policy implications are similar, except that the prescribed durations are shorter than in the baseline calibration, but still longer than current US policy.

Transmission only through economic activities. In the baseline calibration, I assigned an equal likelihood of transmitting the virus through consumption, outside labor, and other channels during the initial stages of the pandemic. I also study the case in which the virus transmits only through economic activities (consumption and outside labor), by setting $\beta_{e}=0$ and adjusting $\beta_{c}=0.12$ and $\beta_{\ell}=21.30$ so that the basic reproduction number remains unchanged at 2.2. In this case, private mitigation alone causes the death rate to fall to 0.5 percent, as seen in the second panel of Table 6 . Even so, the main policy implications are robust to this alternative setting, with a notably larger subsidy amount in the constrained optimal policy configuration that brings the death rate to nearly zero. It is worth noting that this configuration generates levels of deaths that are most in line with the current projections. In the configuration that most resembles current US policy, this version of the model predicts approximately 410,000 and 1 million COVID-19 deaths, by the end of 2020 and 2022, respectively. ${ }^{29}$ One thing to note is that, as shown in Figure 10 (Appendix D), when mitigation is relaxed after four months, as in US policy, there is a second wave in 2021 that results in more deaths than in 2020.

Option to consume from home. I also study an extension of the model in which individuals have the option to consume from home. Specifically, I assume that

$$
u\left(c^{o}, c^{h}, \ell, h\right)=\frac{\left(c^{o}+\phi c^{h}\right)^{1-\sigma}}{1-\sigma}-\varphi \frac{\ell^{1+\nu}}{1+\nu}+\bar{u}+\hat{u}_{h}
$$

where $0 \leq \phi \leq 1$ and that

$$
\pi_{I t}\left(c^{o}, \ell^{o} ; Z_{t}\right)=\beta_{c} c^{o} C_{I t}^{o}+\beta_{\ell} \ell^{o} L_{I t}^{o}+\beta_{e} \mu_{I t},
$$

\footnotetext{
${ }^{29}$ For example, the University of Washington's Institute for Health Metrics and Evaluation projects 427,000 COVID-19 deaths by the end of 2020 in the scenario that the social distancing mandates continue to decline. See https : //covid19.healthdata.org/united-states-of-america?view=total-deaths\&tab=trend (accessed October 5, 2020). At this stage, projections for longer time horizon COVID-19 deaths are subject to large errors.
} 
Table 6: Sensitivity analysis (2)

\begin{tabular}{|c|c|c|c|c|c|c|c|}
\hline & $\begin{array}{l}\text { subsidy } \\
\text { amount } \\
\text { (\$/week) }\end{array}$ & $\begin{array}{l}\text { duration } \\
\text { (months) }\end{array}$ & $\begin{array}{l}\text { threshold } \\
\text { (hours } \\
\text { /week) }\end{array}$ & $\begin{array}{l}\text { lock- } \\
\text { down }\end{array}$ & $\begin{array}{c}\text { average } \\
\text { welfare } \\
\text { change } \\
\text { (percent) }\end{array}$ & $\begin{array}{l}\text { 2-year } \\
\text { output } \\
\text { (index) }\end{array}$ & $\begin{array}{c}\text { deaths } \\
\text { (percent) }\end{array}$ \\
\hline \multicolumn{8}{|c|}{ higher basic reproduction number $\left(R_{0}=2.5\right)$} \\
\hline constrained optimum* & 900 & 14 & 0 & no & -19.2 & 87.5 & 1.8 \\
\hline output maximizing* & 525 & 8 & 0 & no & -21.0 & 95.3 & 2.1 \\
\hline US policy & 600 & 4 & 10 & yes & -20.9 & 87.0 & 2.1 \\
\hline no mitigation & 0 & 0 & none & no & -22.7 & 88.8 & 2.4 \\
\hline \multicolumn{8}{|c|}{ transmission only through economic activities $\left(\beta_{e}=0\right)$} \\
\hline constrained optimum* & 1050 & 18 & 0 & no & -2.9 & 81.2 & 0.1 \\
\hline output maximizing* & 450 & 22 & 0 & no & -5.1 & 97.1 & 0.3 \\
\hline US policy & 600 & 4 & 10 & yes & -6.7 & 87.5 & 0.4 \\
\hline no mitigation & 0 & 0 & none & no & -8.7 & 91.0 & 0.5 \\
\hline \multicolumn{8}{|c|}{ option to consume from home } \\
\hline constrained optimum* & 900 & 22 & 0 & no & -10.3 & 83.2 & 0.7 \\
\hline output maximizing* & 450 & 22 & 0 & no & -11.2 & 95.9 & 0.8 \\
\hline US policy & 600 & 4 & 10 & yes & -12.6 & 88.1 & 1.0 \\
\hline no mitigation & 0 & 0 & none & no & -14.8 & 90.1 & 1.2 \\
\hline \multicolumn{8}{|c|}{ subsidy funded by taxes on consumption and labor income } \\
\hline constrained optimum* & 675 & 22 & 0 & no & -15.5 & 91.4 & 1.3 \\
\hline output maximizing* & 525 & 10 & 0 & no & -17.1 & 95.6 & 1.5 \\
\hline US policy & 600 & 4 & 10 & yes & -17.3 & 85.3 & 1.5 \\
\hline no mitigation & 0 & 0 & none & no & -19.6 & 90.2 & 1.9 \\
\hline \multicolumn{8}{|l|}{ no pandemic } \\
\hline constrained optimum & 0 & 0 & none & no & 0.0 & 100.0 & 0.0 \\
\hline output maximizing & 0 & 0 & none & no & 0.0 & 100.0 & 0.0 \\
\hline US policy & 600 & 4 & 10 & yes & -0.4 & 92.4 & 0.0 \\
\hline no mitigation & 0 & 0 & none & no & 0.0 & 100.0 & 0.0 \\
\hline
\end{tabular}

Notes: Average welfare change reports the population-weighted average of individual consumption equivalents. Output refers to output from $t=1$ (March 27, 2020) to $t=52$ (March 24, 2022), compared with the analogous 52-period output in the steady state, indexed at 100. 
where $C_{I t}^{o}$ denotes aggregate outside consumption of infected individuals. This functional form implies that, for any $\phi<1$, all consumption is outside in the pre-pandemic steady state. Thus the calibration of the model parameters is unaffected by this model extension. In this robustness exercise, I assume that there is a 50 percent utility loss for home consumption relative to outside consumption by setting $\phi=0.5$. For reference, this implies that two months into the pandemic (May 22, 2020), old individuals reduce their outside consumption by 87 percent and young individuals reduce their outside consumption by 10 percent in the no mitigation scenario. As one can expect, allowing for home consumption dramatically reduces the no-mitigation death rate from 1.9 to 1.2 percent, as can be seen in Table 4 and the third panel of Table 6. The main policy implications are mostly unchanged, except that the durations of the mitigation policies of both the constrained optimal and output maximizing configurations are even longer (22 months) relative to the baseline model.

Subsidy funded by taxes on consumption and labor income. In the baseline calibration, I assumed that the stay-at-home subsidy is funded by a tax on consumption. I also study the robustness of the results to assuming that the subsidy is funded by equal increases in the tax rates on consumption and labor income. The main policy implications are nearly unchanged to the baseline, except that the constrained optimal subsidy is closer to that of US policy but for a longer duration, as shown in Table 6.

No pandemic. Given the relatively large, broad, and robust support of the mitigation policies, one might wonder whether such policies would be beneficial in normal times. I find that this is not the case. In fact, when there is no pandemic, there is no policy configuration that delivers higher output or an average welfare gain, let alone one with unanimous support.

\section{Conclusion}

In this paper, I developed a quantitative life cycle-economic epidemiology model that was used to measure the heterogeneous welfare consequences of COVID-19, with and without mitigation policies, and to investigate the properties of optimal mitigation policies. Using the calibrated model, I show that private mitigation plays a substantial role in reducing deaths and output during the pandemic, but there is large heterogeneity in the intensity of 
private mitigation across individuals. In particular, reductions in economic activities that contribute to the spread of COVID-19 are larger for individuals that are older, have higher wages, or have higher wealth. I also show that stay-at-home subsidies are superior to stayat-home orders in that they reduce deaths by more and output by less. Furthermore, the stay-at-home subsidy delivers a higher average welfare gain than the stay-at-home order and benefits all individuals. Finally, it is possible to simultaneously improve economic and public health outcomes, though the constrained optimal policy leans toward saving more lives while causing a slightly lower output relative to no mitigation. 


\section{References}

Alvarez, F., D. Argente, And F. Lippi (2020): "A Simple Planning Problem for COVID-19 Lockdown," Covid Economics, 14, 1-32, https://doi.org/10.3386/w26981.

Argente, D. O., C.-T. Hsieh, And M. LeE (2020): "The Cost of Privacy: Welfare Effect of the Disclosure of COVID-19 Cases," Tech. rep., National Bureau of Economic Research, https://doi.org/10.3386/w27220.

Atkeson, A. (2020): "What will be the economic impact of COVID-19 in the US? Rough estimates of disease scenarios," Tech. rep., National Bureau of Economic Research, https://doi.org/10.3386/w26867.

Aum, S., S. Y. T. LEE, AND Y. SHIN (2020): "Inequality of fear and self-quarantine: Is there a trade-off between GDP and public health?" Covid Economics, 14, 143-174, https://doi.org/10.3386/w27100.

Azzimonti, M., A. Fogli, F. Perri, And M. Ponder (2020): "Pandemic Control in ECON-EPI Networks," Tech. rep., National Bureau of Economic Research, https://doi.org/10.3386/w27741.

Bairoliya, N. AND A. Imrohoroglu (2020): "Macroeconomic Consequences of Stay-At-Home Policies During the COVID-19 Pandemic," Covid Economics, 13, 71-90, https://www.marshall.usc.edu/sites/default/files/bairoliy/intellcont/macroeffects_of_corona1.pdf.

Baqaee, D., E. Farhi, M. J. Mina, And J. H. Stock (2020): "Reopening Scenarios," Tech. rep., National Bureau of Economic Research, https://doi.org/10.3386/w27244.

Berger, D. W., K. F. Herkenhoff, And S. Mongey (2020): "An seir infectious disease model with testing and conditional quarantine," Covid Economics, 13, 1-30, https://doi.org/10.3386/w26901.

Birinci, S., F. Karahan, Y. Mercan, and K. See (2020): "Labor Market Policies during an Epidemic," Tech. rep., https://doi.org/10.20955/wp.2020.024. 
Bodenstein, M., G. Corsetti, And L. Guerrieri (2020): "Social distancing and supply disruptions in a pandemic," Covid Economics, 19, 1-52, https://ssrn.com/abstract $=3594260$.

Bognanni, M., D. Hanley, D. Kolliner, and K. Mitman (2020): "Economic Activity and COVID-19 Transmission: Evidence from an Estimated Economic-Epidemiological Model," Tech. rep., University of Pittsburgh, https://doughanley.com/files/papers/COVID.pdf.

Brodeur, A., D. M. Gray, A. Islam, and S. Bhuiyan (2020): "A Literature Review of the Economics of COVID-19," Tech. rep., https://ssrn.com/abstract=3636640.

Carroll, D. and S. Hur (2020): "On the distributional effects of international tariffs," Tech. rep., Federal Reserve Bank of Cleveland, https://doi.org/10.26509/frbc-wp-202018.

Chari, V. V., R. Kirpalani, and C. Phelan (2020): "The hammer and the scalpel: On the economics of indiscriminate versus targeted isolation policies during pandemics," Tech. rep., National Bureau of Economic Research, https://doi.org/10.3386/w27232.

Chetty, R., J. N. Friedman, N. Hendren, M. Stepner, et Al. (2020): "How did covid-19 and stabilization policies affect spending and employment? a new real-time economic tracker based on private sector data," Tech. rep., National Bureau of Economic Research, https://doi.org/10.3386/w27232.

Dingel, J. I. And B. Neiman (2020): "How many jobs can be done at home?" Covid Economics, 1, 16-24, https://doi.org/10.3386/w26948.

Eichenbaum, M. S., S. Rebelo, And M. Trabandt (2020): "The macroeconomics of epidemics," Tech. rep., National Bureau of Economic Research, https://doi.org/10.3386/w26882.

Farboodi, M., G. Jarosch, And R. Shimer (2020): "Internal and external effects of social distancing in a pandemic," Covid Economics, 9, 22-58, https://doi.org/10.3386/w27059. 
Fauci, A. S., H. C. Lane, and R. R. Redfield (2020): "Covid-19navigating the uncharted," New England Journal of Medicine, 382, 1268-1269, https://doi.org/10.1056/NEJMe2002387.

Ferguson, N. M., D. A. Cummings, C. Fraser, J. C. Cajka, P. C. Cooley, and D. S. BuRke (2006): "Strategies for mitigating an influenza pandemic," Nature, 442, 448-452, https://doi.org/10.1038/nature04795.

Floden, M. And J. Lindé (2001): "Idiosyncratic risk in the United States and Sweden: Is there a role for government insurance?" Review of Economic dynamics, 4, 406-437, https://doi.org/10.1006/redy.2000.0121.

Garibaldi, P., E. R. Moen, and C. A. Pissarides (2020): "Modelling contacts and transitions in the SIR epidemics model," Covid Economics, 5, 1-20, https://www.carloalberto.org/wp-content/uploads/2020/04/garibaldi.pdf.

Glover, A., J. Heathcote, D. Krueger, and J.-V. Rios-Rull (2020): "Health versus Wealth: On the Distributional Effects of Controlling a Pandemic," Covid Economics, 6, 22-64, https://doi.org/10.1006/redy.2000.0121.

Greenstone, M. And V. Nigam (2020): "Does Social Distancing Matter?" Tech. rep., University of Chicago, Becker Friedman Institute for Economics Working Paper, https://dx.doi.org/10.2139/ssrn.3561244.

Hur, S. (2018): "The lost generation of the Great Recession," Review of Economic Dynamics, 30, 179-202, https://doi.org/10.1016/j.red.2018.05.004.

Hur, S. And M. Jenuwine (2020): "Lessons on the Economics of Pandemics from Recent Research," Economic Commentary, https://doi.org/10.26509/frbc-ec-202011.

Jones, C., T. Philippon, And V. Venkateswaran (2020): "Optimal Mitigation Policies in a Pandemic: Social Distancing and Working from Home," Tech. rep., https://doi.org/10.3386/w26984.

Kapicka, M. And P. Rupert (2020): "Labor markets during pandemics," Tech. rep., UC Santa Barbara. 
Kaplan, G., B. Moll, and G. L. Violante (2020): "The Great Lockdown and the Big Stimulus: Tracing the Pandemic Possibility Frontier for the US," Tech. rep., National Bureau of Economic Research, https://doi.org/10.3386/w27794.

Kermack, W. O. And A. G. McKendrick (1927): "A contribution to the mathematical theory of epidemics," Proceedings of the royal society of london. Series A, Containing papers of a mathematical and physical character, 115, 700-721, https://doi.org/10.1098/rspa.1927.0118.

Kopecky, K. A. And R. M. Suen (2010): "Finite state Markov-chain approximations to highly persistent processes," Review of Economic Dynamics, 13, 701-714, https://doi.org/10.1016/j.red.2010.02.002.

Krueger, D., K. Mitman, and F. Perri (2016): "Macroeconomics and household heterogeneity," in Handbook of Macroeconomics, Elsevier, vol. 2, 843-921, https://doi.org/10.1016/bs.hesmac.2016.04.003.

Krueger, D., H. Uhlig, And T. Xie (2020): "Macroeconomic dynamics and reallocation in an epidemic," Covid Economics, 5, 21-55, https://doi.org/10.3386/w27047.

Moreland, A., C. Herlihy, M. A. Tynan, et Al. (2020): "Timing of State and Territorial COVID-19 Stay-at-Home Orders and Changes in Population Movement-United States, March 1-May 31, 2020," Morbidity and Mortality Weekly Report, 69, https://www.cdc.gov/mmwr/volumes/69/wr/mm6935a2.htm.

Mossong, J., N. Hens, M. Jit, P. Beutels, K. Auranen, R. Mikolajczyk, M. Massari, S. Salmaso, G. S. Tomba, J. Wallinga, et al. (2008): "Social contacts and mixing patterns relevant to the spread of infectious diseases," PLoS medicine, 5, https://doi.org/10.1371/journal.pmed.0050074.

Piguillem, F. And L. Shi (2020): "The Optimal COVID-19 Quarantine and Testing Policies," Tech. rep., Einaudi Institute for Economics and Finance (EIEF), http://www.eief.it/eief/images/WP_20.04.pdf.

U.S. Environmental Protection Agency (2015): "Regulatory Impact Analysis for the Clean Power Plan Final Rule," Tech. rep., 
https://www3.epa.gov/ttnecas1/docs/ria/utilities_ria_final-clean-power-plan-existingunits_2015-08.pdf.

- (2020): "Mortality Risk Valuation," Tech. rep., https://www.epa.gov/environmentaleconomics/mortality-risk-valuation.

Wang, H., Z. Wang, Y. Dong, R. Chang, C. Xu, X. Yu, S. Zhang, L. Tsamlag, M. Shang, J. Huang, et AL. (2020): "Phase-adjusted estimation of the number of coronavirus disease 2019 cases in Wuhan, China," Cell Discovery, 6, 1-8, https://doi.org/10.1038/s41421-020-0148-0. 


\section{A Estimation of wage processes}

The sample selection and estimation procedure closely follows the procedure described in Krueger et al. (2016) and Hur (2018). I use annual income data from the PSID core sample (1970-1997), selecting all household heads, ages 23 to 64. For waves before 1993, I use the variable Total Labor Income of Head, which is the sum of wages, tips, labor part of farm and business income, and other items. For waves after 1993, I compute total head labor income as the sum of the head's labor income (excluding farm and business income), head's labor part of business income, and 50 percent of household farm income, divided by two if married.

Next, I construct wages by dividing head's total labor income by hours, where hours is the sum of hours worked, hours unemployed, and sick hours. I drop observations with missing education, with wages that are less than half of the minimum wage, with top-coded income, and with fewer than 1,000 hours per year. On this sample, I regress the log wage on age and education dummies, their interaction, and year dummies. I then exclude all individual wage sequences shorter than 5 years, leaving final samples of 4,524 individuals, with an average length of 9 years. On these samples, I compute the autocovariance matrix of the residuals. The stochastic process in equation (20) is estimated using GMM, targeting the covariance matrix, where the weighting matrix is the identity matrix. I thank Chris Tonetti for providing the Matlab routines that perform the estimation.

\section{B Definition of equilibrium with transition}

First, the Bellman equations need to be modified to include the mitigation policies. Given the sequence of policies $\left\{\tau_{c t}, x_{t}, \bar{\ell}, \bar{\ell}_{t}^{o}, \tau_{\ell}, s\right\}_{t=1}^{\infty}$ and aggregate states $Z_{t} \equiv\left\{\mu_{I t}, C_{I t}, L_{I t}^{o}\right\}$, a retiree with age $j \geq J_{R}$, wealth $k$, and health $h$ in period $t$ solves:

$$
\begin{array}{rl}
v_{j t}^{R}(k, h)=\max _{c, k^{\prime} \geq 0} & u(c, 0, h)+\beta \psi_{j} \sum_{h^{\prime} \in H} \Pi_{h h^{\prime} t}\left(c, 0 ; Z_{t}\right) v_{j+1, t+1}^{R}\left(k^{\prime}, h^{\prime}\right) \\
& +\beta\left(1-\psi_{j}\right) \sum_{h^{\prime} \in H} \Pi_{h h^{\prime} t}\left(c, 0 ; Z_{t}\right) v_{j, t+1}^{R}\left(k^{\prime}, h^{\prime}\right) \\
\text { s.t. }\left(1+\tau_{c t}\right) c+k^{\prime} \leq s+k\left(1+r_{t}\right)
\end{array}
$$


and a worker with age $j<J_{R}$, wealth $k$, efficiency $\varepsilon$, and health $h$ in period $t$ solves:

$$
\begin{array}{rl}
v_{j t}(k, \varepsilon, h)=\max _{c, \ell, \ell^{o}, k^{\prime} \geq 0} & u(c, \ell, h)+\beta \psi_{j} \sum_{\varepsilon^{\prime} \in E h^{\prime} \in H} \sum_{\varepsilon \varepsilon^{\prime}} \Pi_{h h^{\prime} t}\left(c, \ell^{o} ; Z_{t}\right) v_{j+1, t+1}\left(k^{\prime}, \varepsilon^{\prime}, h^{\prime}\right) \\
& +\beta\left(1-\psi_{j}\right) \sum_{\varepsilon^{\prime} \in E h^{\prime} \in H} \sum_{\varepsilon \varepsilon^{\prime}} \Pi_{h h^{\prime} t}\left(c, \ell^{o} ; Z_{t}\right) v_{j, t+1}\left(k^{\prime}, \varepsilon^{\prime}, h^{\prime}\right) \\
\text { s.t. } & \left(1+\tau_{c t}\right) c+k^{\prime} \leq w \eta_{j}^{h}\left(1-\tau_{\ell}\right) \varepsilon \ell+x_{t} \mathbb{1}_{\ell<\bar{\ell}}+k(1+r) \\
& \left(1-\bar{\theta}_{j}(\varepsilon)\right) \ell \leq \ell^{o} \leq \bar{\ell}_{t}^{o} .
\end{array}
$$

The solution yields value and policy functions that depend on time since the policies and aggregate states $Z_{t}$ are time varying. Note that variables that are not denoted by time are fixed at their pre-pandemic steady state values. The constant price assumption is akin to assuming the free flow of goods and capital in a small open economy environment.

Definition. A competitive equilibrium, given an initial distribution $\left\{\mu_{j 1}^{*}\right\}_{j \in J}$ and fiscal policies $\left\{\tau_{c t}, x_{t}, \bar{\ell}, \bar{\ell}_{t}^{o}, \tau_{\ell}, s\right\}_{t=1}^{\infty}$, is a sequence of value functions $\left\{\left\{v_{j t}\right\}_{j \in J}\right\}_{t=1}^{\infty}$, policy functions $\left\{\left\{c_{j t}, \ell_{j t}, \ell_{j t}^{o}, k_{j t}^{\prime}\right\}_{j \in J}\right\}_{t=1}^{\infty}$, prices $\{w, r\}$, producer plans $\left\{Y_{f t}, L_{f t}, K_{f t}\right\}_{t=1}^{\infty}$, the distribution of newborns $\omega$, and measures $\left\{\left\{\mu_{j t}\right\}_{j \in J}\right\}_{t=1}^{\infty}$ such that, for all $t \geq 1$ :

1. Given prices, retirees and workers solve (28) and (29), respectively.

2. Given prices, firms solve (8).

3. Labor markets clear:

$$
L_{f t}=\int_{X} \sum_{j<J_{R}} \ell_{j t}(k, \varepsilon, h) d \mu_{j t}(k, \varepsilon, h) .
$$

4. The government budget for mitigation policies clears in present value:

$$
\begin{aligned}
& \sum_{t=1}^{\infty}\left\{(1+r)^{1-t} \tau_{c t} \int_{X} \sum_{j \in J} c_{j t}(k, \varepsilon, h) d \mu_{j t}(k, \varepsilon, h)\right\} \\
& =\sum_{t=1}^{\infty}\left\{(1+r)^{1-t} x_{t} \int_{X} \mathbb{1}_{\left\{\ell_{j t}(k, \varepsilon, h) \leq \bar{\ell}\right\}} \sum_{j<J_{R}} d \mu_{j t}(k, \varepsilon, h)\right\} .
\end{aligned}
$$

5. For any subset $(\mathcal{K}, \mathcal{E}, \mathcal{H}) \in \mathcal{B}$, the measure $\mu_{j t}$ satisfies, for $j>1$,

$$
\begin{aligned}
\mu_{j t}(\mathcal{K}, \mathcal{E}, \mathcal{H}) & =\int_{X} \psi_{j-1} \mathbb{1}_{\left\{k_{j-1, t-1}^{\prime}(k, \varepsilon, h) \in \mathcal{K}\right\}} \sum_{\varepsilon^{\prime} \in \mathcal{E} h^{\prime} \in \mathcal{H}} \sum_{\varepsilon \varepsilon^{\prime}} \Pi_{h h^{\prime}} d \mu_{j-1, t-1}(k, \varepsilon, h) \\
& +\int_{X}\left(1-\psi_{j}\right) \mathbb{1}_{\left\{k_{j, t-1}^{\prime}(k, \varepsilon, h) \in \mathcal{K}\right\}} \sum_{\varepsilon^{\prime} \in \mathcal{E} h^{\prime} \in \mathcal{H}} \sum_{\varepsilon \varepsilon^{\prime}} \Pi_{h h^{\prime}} d \mu_{j, t-1}(k, \varepsilon, h)
\end{aligned}
$$


and

$$
\begin{aligned}
\mu_{1 t}(\mathcal{K}, \mathcal{E}, \mathcal{H}) & =\int_{X}\left(1-\psi_{1}\right) \mathbb{1}_{\left\{k_{1, t-1}^{\prime}(k, \varepsilon, h) \in \mathcal{K}\right\}} \sum_{\varepsilon^{\prime} \in \mathcal{E} h^{\prime} \in \mathcal{H}} \sum_{\varepsilon \varepsilon^{\prime}} \Pi_{h h^{\prime}} d \mu_{1, t-1}(k, \varepsilon, h) \\
& +\omega(\mathcal{K}, \mathcal{E}, \mathcal{H}) .
\end{aligned}
$$

\section{Computational appendix}

The solution algorithm broadly consists of two steps:

1. Solve for the pre-pandemic steady state.

2. Solve for pandemic transition path that ends in (1).

In each step, I solve the household problem over an unevenly spaced grid of 120 wealth points, $k_{\text {coarse }}$. To improve solution accuracy and to save time, I place more points near the borrowing constraint, where the household value function is more concave. I store the equilibrium wealth distribution as a histogram over an unevenly spaced wealth grid of 2000 points, $k_{\text {fine }}$. I set the maximum wealth level on $k_{\text {fine }}$ much lower than the one on $k_{\text {coarse }}$ and check that this upper bound is not overly restrictive by verifying that the equilibrium distribution has no mass on the highest grid point in the steady state or at any point along the transition.

To calibrate, I guess a vector of parameters $\left[\beta, \varphi, \bar{u}, s, \tau_{\ell}, \beta_{c}, \beta_{\ell}, \beta_{e}, \hat{u}_{I},\right]$. I then solve for the pre-pandemic steady state, calculate the model-implied values for the targets, and update the guess using a quasi-Newton method with some dampening.

\section{C.1 Solving for a steady state}

1. Let $\mu_{j}^{i n i t}(k, \varepsilon, h)$ be an initialization of the distribution over $k_{f i n e}, H$, and $E$.

2. Solve for the equilibrium rental rate, $r^{\star}$.

(a) Guess at $r^{0}$.

(b) Given $r^{0}$, use equations (9) and (10) to get the wage,

$$
w^{0}\left(r^{0}\right)=(1-\alpha)\left(\frac{r+\delta}{\alpha}\right)^{\frac{\alpha}{\alpha-1}} .
$$


(c) Starting at $j=\bar{J}$, iterate on the Bellman equation in (28) until the value function converges to find the retiree value and policy functions conditional on prices. Repeat for $j=\bar{J}-1, \ldots, J^{R}$ if $\bar{J}>J^{R}$.

(d) Starting at $j=J^{R}-1$, iterate on the Bellman equation in (6) until the value function converges to find the worker value and policy functions conditional on prices. Repeat for $j=J^{R}-2, . ., 1$ if $J^{R}>2$.

(e) Use linear interpolation to map the value and policy functions from $k_{\text {coarse }}$ onto $k_{\text {fine }}$.

(f) Beginning at $\mu_{j}^{i n i t}$, update the distribution using equations (14)-(15) and the fine-grid decision rules for saving. Repeat until $\mu_{j}$ converges to $\mu_{j}^{\star}\left(r^{0}\right)$.

(g) Use $\mu_{j}^{\star}$ and the fine-grid decision rules to compute all aggregates.

(h) Find the implied interest rate, $\bar{r}^{0}=\alpha\left(\frac{K^{0}}{L^{0}}\right)^{\alpha-1}-\delta$.

(i) Use Brent's method to solve for $r^{\star}$ over a fixed interval.

\section{C.2 Solving for a transition path}

Assume that a vaccine and cure is fully implemented in $t=\hat{t}$ and that prices are fixed at their initial steady state values throughout the transition path. This implies that, even though the measure $\mu_{j t}$ takes a very long time to return to its steady state values, value and policy functions only need to be solved for $t \leq \hat{t}$ since all the relevant variables for solving the individual's optimization problem are constant for $t>\hat{t}$. The constant price assumption is akin to assuming the free flow of goods and capital in a small open economy environment.

To introduce COVID-19 in the economy, set $\mu_{j 1}(k, \varepsilon, I)=0.0075 \mu_{j}(k, \varepsilon, S), \mu_{j 1}(k, \varepsilon, S)=$ $0.9925 \mu_{j}(k, \varepsilon, S)$, and $\mu_{j 1}(k, \varepsilon, R)=0$ for $j \in J$ and $k \in K$. Recall that all agents are susceptible in the pre-pandemic steady state.

1. Guess the sequence $\left\{Z_{t}, \tau_{c t}\right\}_{t=1}^{\hat{t}}$.

2. Set $v_{j, \hat{t}+1}$ equal to the steady-state value function for $j \in J$. Then, starting in period $\hat{t}$, solve the Bellman equations in (28) and (29) backward. This produces a sequence of policy functions for periods $t=1, . ., \hat{t}$. 
3. Starting at $\mu_{j, t=1}$, simulate forward using the household policy functions to find the sequence of measures from $t=1, \ldots, T$. Along the way, solve for aggregate variables in each period, including $\bar{Z}_{t} \equiv\left\{\mu_{I t}, C_{I t}, L_{I t}^{o}\right\}$.

4. Check that the difference between the guess for $\left\{Z_{t}\right\}$ and the implied value $\left\{\bar{Z}_{t}\right\}$ (measured under the sup norm) is less than a small tolerance. Additionally, if $x>0$, check that the government budget for mitigation policies in (31) clears in present value. If so, a transition path has been found.

5. If not, update the guess using a dampening method and repeat.

\section{Additional figures}


Figure 9: Response to pandemic (stay-at-home order)

(a) Consumption

(young, susceptible)

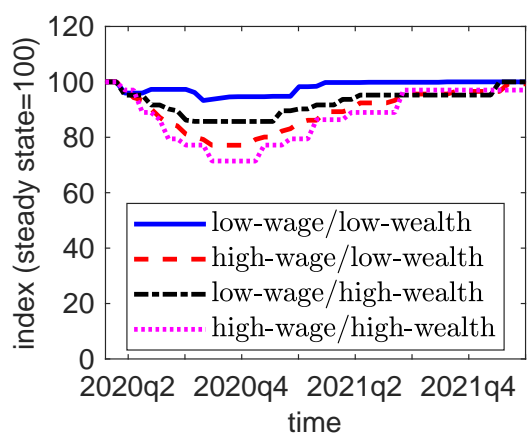

(d) Outside hours

(young, susceptible)

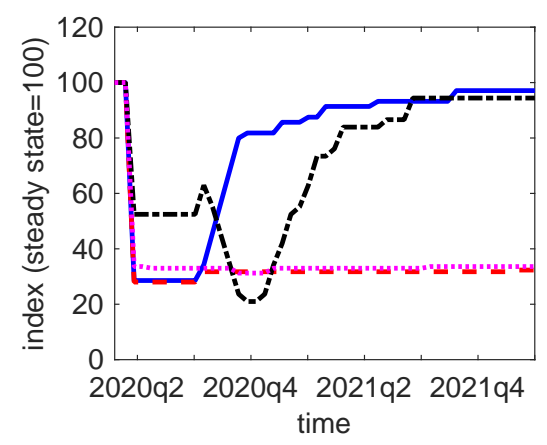

(b) Consumption

(middle, susceptible)

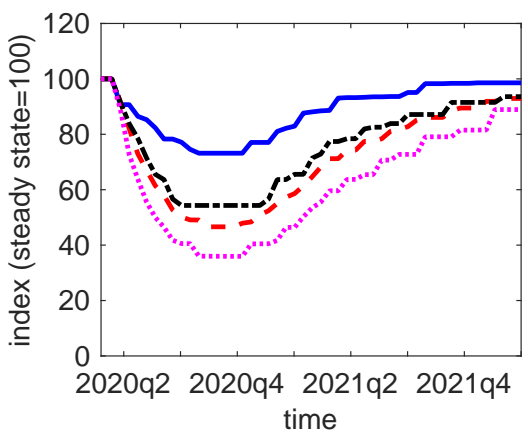

(e) Outside hours

(middle, susceptible)

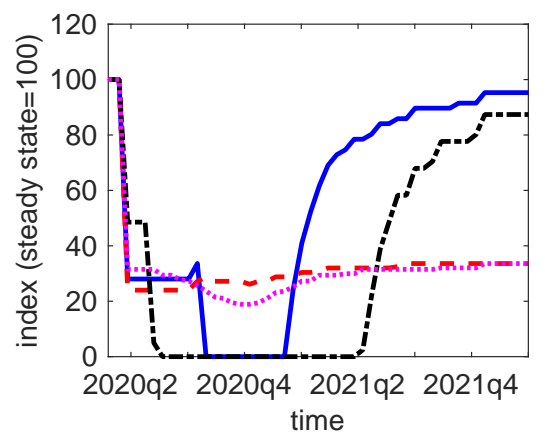

(c) Consumption

(old, susceptible)

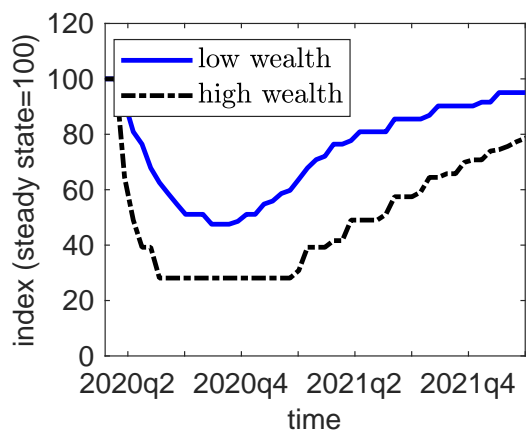

(f) Current infections

by age

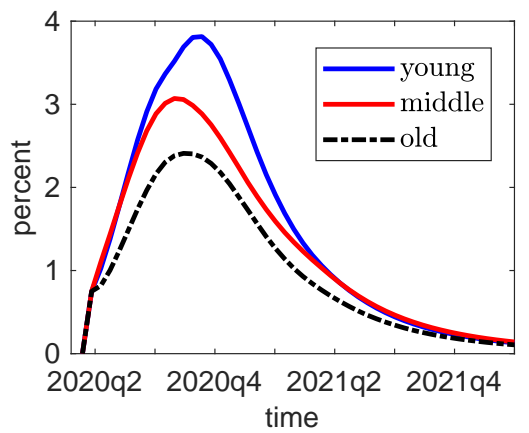

Notes: Low income and high income correspond to 10th and 90th percentiles of the steady state wage distribution, respectively. Low wealth and high wealth correspond to the 25 th and 75 th percentiles of the steady state wealth distribution, respectively. 
Figure 10: Disease transmission and aggregates (economic transmission only, $\beta_{e}=0$ )

(a) Reproduction number

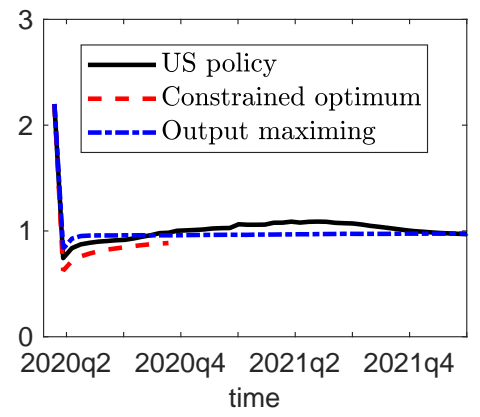

(d) Aggregate consumption

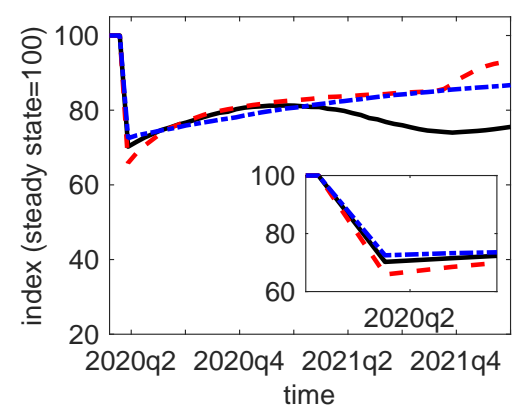

(b) Current infections

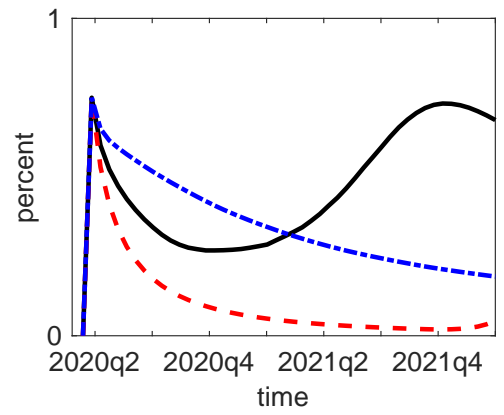

(e) Aggregate outside hours

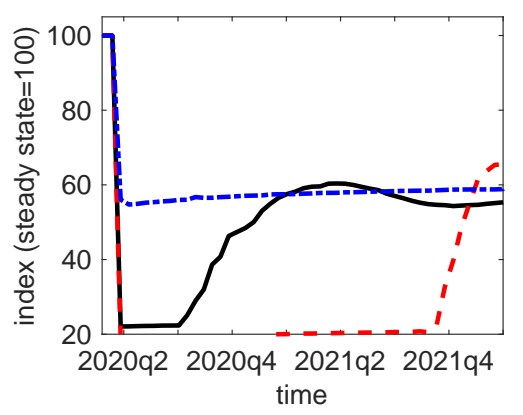

(c) Cumulative deaths

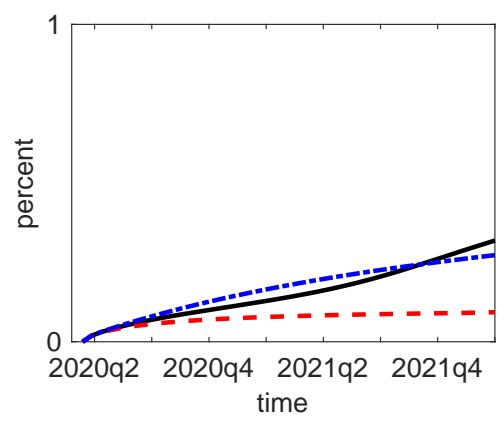

(f) Aggregate output

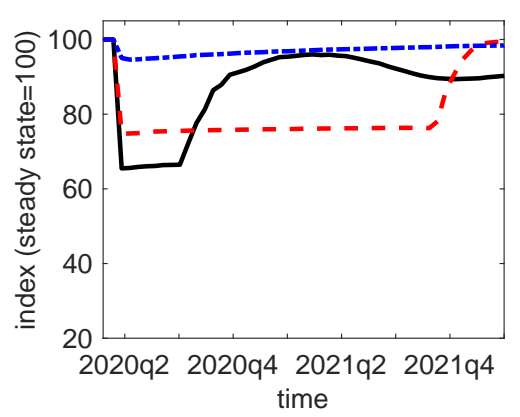

